\title{
The impact of planetary waves on the latitudinal displacement of sudden stratospheric warmings
}

\author{
V. Matthias ${ }^{1}$, P. Hoffmann ${ }^{1}$, A. Manson ${ }^{2}$, C. Meek ${ }^{2}$, G. Stober ${ }^{1}$, P. Brown ${ }^{3}$, and M. Rapp ${ }^{4, *}$ \\ ${ }^{1}$ Leibniz-Institute of Atmospheric Physics at the Rostock University, Schloss-Str. 6, 18225 Kühlungsborn, Germany \\ ${ }^{2}$ Institute of Space and Atmospheric Studies, University of Saskatchewan, 116 Science Place, Saskatoon, Sask. S7N5E2, \\ Canada \\ ${ }^{3}$ Canada Research Chair in Meteor Science, Department of Physics and Astronomy, University of Western Ontario, London, \\ Ontario N6A 3K7, Canada \\ ${ }^{4}$ Deutsches Zentrum für Luft- und Raumfahrt, Institut für Physik der Atmosphäre, Oberpfaffenhofen, Germany \\ *also at: Meteorologisches Institut München, Ludwig-Maximilian Universität München, Munich, Germany
}

Correspondence to: V. Matthias (matthias@iap-kborn.de)

Received: 18 April 2013 - Revised: 19 June 2013 - Accepted: 20 June 2013 - Published: 9 August 2013

\begin{abstract}
The Northern Hemispheric winter is disturbed by large scale variability mainly caused by Planetary Waves (PWs), which interact with the mean flow and thus result in Sudden Stratospheric Warmings (SSWs). The effects of a SSW on the middle atmosphere are an increase of stratospheric and a simultaneous decrease of mesospheric temperature as well as a wind reversal to westward wind from the mesosphere to the stratosphere. In most cases these disturbances are strongest at polar latitudes, get weaker toward the south and vanish at mid-latitudes around $50^{\circ}$ to $60^{\circ} \mathrm{N}$ as for example during the winter 2005/06. However, other events like in 2009, 2010 and 2012 show a similar or even stronger westward wind at mid- than at polar latitudes either in the mesosphere or in the stratosphere during the SSW. This study uses local meteor and MF-radar measurements, global satellite observations from the Microwave Limb Sounder (MLS) and assimilated model data from MERRA (ModernERA Retrospective analysis for research and Applications). We compare differences in the latitudinal structure of the zonal wind, temperature and PW activity between a "normal" event, where the event in 2006 was chosen representatively, and the latitudinal displaced events in 2009, 2010 and 2012. A continuous westward wind band between the pole and $20^{\circ} \mathrm{N}$ is observed during the displaced events. Furthermore, distinctive temperature differences at mid-latitudes occur before the displaced warmings compared to 2006 as well as a southward extended stratospheric warming after-
\end{abstract}

wards. These differences between the normal SSW in 2006 and the displaced events in 2009, 2010 and 2012 are linked to an increased PW activity between $30^{\circ} \mathrm{N}$ and $50^{\circ} \mathrm{N}$ and the changed stationary wave flux in the stratosphere around the displaced events compared to 2006.

Keywords. Meteorology and atmospheric dynamics (middle atmosphere dynamics; waves and tides)

\section{Introduction}

Sudden Stratospheric Warmings (SSWs) are known as exceptional polar vertical coupling processes during winter, affecting all atmospheric layers. They are caused by an upward propagation of Planetary Waves (PWs) and their interaction with the mean flow (for details see Matsuno, 1971, and Andrews et al., 1987, Chapt. 6). SSWs can be classified into 3 different types (Labitzke and Naujokat, 2000): major, minor and Canadian warmings. This classification is based on the response of the zonal mean zonal wind (weakening, reversal) at $60^{\circ} \mathrm{N}$ and the temperature gradient between $60^{\circ}$ and $90^{\circ} \mathrm{N}$, both at $10 \mathrm{hPa}$. A large number of studies describe the individual response of SSWs on the middle atmosphere regarding the dynamical and thermal structure, especially of the record warming in 2009, e.g. Manney et al. (2009), Kurihara et al. (2010) and Shepherd et al. (2009). 
In connection with SSWs, a weakening or reversal of the dominating eastward zonal winds to summerly westward winds in the Mesosphere/Lower Thermosphere (MLT) region has first been observed by Gregory and Manson (1975). This effect is more pronounced at high northern latitudes (e.g. Manson et al., 2006) than at southern or mid-latitudes. To illuminate the contribution of PWs on the MLT during SSWs, Coy et al. (2011) used a data assimilation system covering the 0 to $90 \mathrm{~km}$ altitude range to investigate the temporal development of PWs during the record breaking SSW 2009 and their interaction with the mean flow. Summarising their results, they found a transient non-stationary wave 2 propagating rapidly from the troposphere into the upper mesosphere, where it dissipated and produced easterly mean-flow accelerations which intensified the SSW.

More general statements about the main characteristics of SSWs in the tropo- and stratosphere are made by Charlton and Polvani (2007). They compared the composite analysis of vortex displacement and splitting events between 1958 and 2002 from reanalysis data and found differences in the seasonal distribution as well as in the tropospheric and stratospheric structure. Multi-year observations are used by Matthias et al. (2012) to characterise the average behaviour of SSW-related wave activity in the MLT region. From a composite analysis of 5 major warmings between 1999 and 2010 they found a strong 10-day wave (period: 8-12 d) simultaneous with the warming and a weaker 16-day (period: 12-20 d) wave before.

The effects of SSWs like zonal wind reversal, temperature increase/ decrease and elevated stratopause are strongest at polar latitudes and get weaker toward the south in most cases, see for example Limpasuvan et al. (2004), Hoffmann et al. (2002, 2007) and Manney et al. (2007). However, some stratospheric warming events occur similarly strong or even stronger at mid- than at high latitudes. During the DYANA campaign in 1990, for example, Cevolani (1991) and Singer et al. (1994) found a strong perturbation of the zonal wind between the upper stratosphere and lower thermosphere at mid-latitudes which was in some cases similarly strong compared to higher latitudes (see Singer et al., 1994). A more current event was studied by Stober et al. (2012) where a stronger wind reversal was observed at mid- than at high latitudes during the SSW event of 2010. This mid-latitudinal wind reversal in 2010 was also observed in MF radar winds by Chen et al. (2012) over Langfang ( $\left.39^{\circ} \mathrm{N}, 166^{\circ} \mathrm{E}\right)$.

Fritz and Soules (1970) were the first who found temperature anomalies in the tropical stratosphere during the SSW of 1970 with the help of global satellite data. More recently observations of stratospheric and mesospheric tropical anomalies during the winter 2004/05 were made by Shepherd et al. (2007). A composite analysis of reanalysis data by Kodera (2006) also shows a clear effect of SSWs on the equatorial stratospheric temperature. Therefore, SSWs affect not only mid- and high latitudes, but can also affect the circulation at low latitudes.
Strong mid-latitudinal dynamical disturbances occur not in the majority of SSWs. An obvious question is: under which circumstances are such effects observable at mid- and lower latitudes? To address this question we compare the latitudinal and altitudinal variability of zonal wind reversal and temperature changes for different SSW events. Such an analysis was partly made by Chen et al. (2012) for the SSW in 2010. These authors considered MLS gradient winds and investigated their latitudinal structure. However, they did not offer a possible explanation for this phenomenon.

Since the main reason for SSWs are upward and poleward propagating PWs interacting with the mean flow (see Matsuno, 1971; Andrews et al., 1987) it is tempting to speculate that latitudinal differences in the PW activity might be one reason for the increased mid-low-latitudinal SSW effects during some events. In this work we will therefore investigate the latitudinal variability of the zonal wind reversal and of the temperature changes related to the PW activity.

In detail this article deals with the question: how does the PW behaviour affect the latitudinal expansion of a SSW? We therefore compare 3 SSW events in 2009, 2010 and 2012, where the zonal wind reversal reaches down to lower latitudes, with the SSW of 2006, where the zonal wind reversal is strongest at the pole and weakens towards mid-latitudes but does not occur at lower latitudes, as the "normal" case. We investigate the zonal wind reversal at different latitudes and altitudes with the help of MF- and meteor radar measurements at different latitudinal and longitudinal locations and assimilated model data from MERRA (Modern-ERA Retrospective analysis for research and Applications). Furthermore we use global temperature and geopotential height data from the Microwave Limb Sounder (MLS) for northern hemispheric temperature variations and for an estimation of PWs characteristics.

Note that there are only very few studies considering the latitudinal extension of circulation changes during and after SSWs. Most of them are based on model simulations, e.g. carried out with the WACCM model (De La Torre et al., 2012; Limpasuvan et al., 2012) or with the Japanese T213L256GCM (Tomikawa et al., 2012). With WACCM, an enhanced effect of SSW on the circulation at latitudes south of $40^{\circ} \mathrm{N}$ has been found in connection with splitting events. Additionally, Tomikawa et al. (2012) and Limpasuvan et al. (2012) used their simulation to estimate the latitudinal-pressure dependence of the Eliassen-Palm flux and its divergence for all wave numbers which shows an enhancement during and after the simulated major warmings. In contrast to the above mentioned model simulations, we use observational radar and satellite data together with assimilated MERRA data during four SSW events in this study.

Section 2 provides an overview of the used instruments and model data as well as data analysis methods. The comparison of the zonal wind, temperature and PW activity at different latitudes from radar and satellite measurements and 
Table 1. Technical details of Meteor radar systems at Tavistock (CMOR), Juliusruh, Andenes and Eureka.

\begin{tabular}{|c|c|c|c|c|}
\hline & $\begin{array}{c}\text { Tavistock } \\
(\mathrm{CMOR}) \\
\left(43^{\circ} \mathrm{N}, 81^{\circ} \mathrm{W}\right)\end{array}$ & $\begin{array}{c}\text { Juliusruh } \\
\left(55^{\circ} \mathrm{N}, 13^{\circ} \mathrm{E}\right)\end{array}$ & $\begin{array}{c}\text { Andenes } \\
\left(69^{\circ} \mathrm{N}, 16^{\circ} \mathrm{E}\right)\end{array}$ & $\begin{array}{c}\text { Eureka } \\
\left(80^{\circ} \mathrm{N}, 86^{\circ} \mathrm{W}\right)\end{array}$ \\
\hline Frequency & $\begin{array}{c}17.45,29.85 \\
38.15 \mathrm{MHz}\end{array}$ & $32.55 \mathrm{MHz}$ & $32.55 \mathrm{MHz}$ & $32.55 \mathrm{MHz}$ \\
\hline Power & $\begin{array}{c}6 \mathrm{~kW} \\
\text { (per frequency) }\end{array}$ & $12 \mathrm{~kW}$ & $18 \mathrm{~kW}$ & $12 \mathrm{~kW}$ \\
\hline PRF & 532 & 2114 & 2094 & 2094 \\
\hline Coherent integ. & 1 & 4 & 4 & 4 \\
\hline Height range & $70-120 \mathrm{~km}$ & $80-100 \mathrm{~km}$ & $80-100 \mathrm{~km}$ & $80-100 \mathrm{~km}$ \\
\hline Sampling resol. & $3 \mathrm{~km}$ & $2 \mathrm{~km}$ & $2 \mathrm{~km}$ & $2 \mathrm{~km}$ \\
\hline Wind analysis & DBS & DBS & DBS & DBS \\
\hline Observation since & 1999-today & 2007-today & 2001-today & 2007-today \\
\hline
\end{tabular}

model data of the considered years is shown in Sect. 3 and discussed in Sect. 4. The results are summarised in Sect. 5.

\section{Experimental data and methods}

\subsection{Radar measurements}

For this study 4 Meteor Radars (MR) located at Andenes $\left(69^{\circ} \mathrm{N}, 16^{\circ} \mathrm{E}\right)$, Juliusruh $\left(55^{\circ} \mathrm{N}, 13^{\circ} \mathrm{E}\right)$, Eureka $\left(80^{\circ} \mathrm{N}\right.$, $\left.86^{\circ} \mathrm{W}\right)$ and at Tavistock $\left(43^{\circ} \mathrm{N}, 81^{\circ} \mathrm{W}\right)$, named Canadian Meteor Orbit Radar (CMOR) as well as 2 Medium Frequency radars (MF-radar), located at Juliusruh and Saskatoon $\left(52^{\circ} \mathrm{N}, 107^{\circ} \mathrm{W}\right)$ are used to investigate the latitudinal differences of zonal wind, mesospheric temperature and planetary wave activity between mid and polar latitudes. An overview of the radar locations is given in Fig. 1. Note that in Andenes a MR and MF-radar are colocated, but in this study only MR data is used. A short description of the MF-radar and afterwards of the MR follows.

Basic parameters of all MF-radars used in this study are summarised in Table 2.

The MF-radar at Juliusruh operates at a frequency of $3.17 \mathrm{MHz}$ with a peak power of $128 \mathrm{~kW}$. Thirteen interconnected narrow-beam cross dipoles (arranged as a Mills Cross) transmit radio wave pulses of $4 \mathrm{~km}$ length and $\sim 15^{\circ}$ width. The reception of the atmospheric signal occurs by four crossed horizontal dipoles close to the Mills Cross. This system has been measuring wind continuously since 2003 and is an enhancement of the MF-radar system which operated at the same place with slightly different characteristics from 1990 to spring 2003. For more information about the development of both MF-radar systems at Juliusruh and their features see Keuer et al. (2007).

The Saskatoon MF-radar operates at a frequency of $2.22 \mathrm{MHz}$ with a peak power of $20 \mathrm{~kW}$. It consists of four spaced receiving arrays and a transmitter antenna with a full beam width of $\sim 15^{\circ}$. Wind measurements have been conducted since 1978 between 60 and $110 \mathrm{~km}$ with a height res-
Table 2. Technical details of MF-radar systems at Saskatoon and Juliusruh.

\begin{tabular}{lcc}
\hline & $\begin{array}{c}\text { Saskatoon } \\
\left(52^{\circ} \mathrm{N}, 107^{\circ} \mathrm{W}\right)\end{array}$ & $\begin{array}{c}\text { Juliusruh } \\
\left(55^{\circ} \mathrm{N}, 13^{\circ} \mathrm{E}\right)\end{array}$ \\
\hline Radar & $\mathrm{MF}$ & $\mathrm{MF}$ \\
Frequency & $2.22 \mathrm{MHz}$ & $3.17 \mathrm{MHz}$ \\
Peak power & $20 \mathrm{~kW}$ & $128 \mathrm{~kW}$ \\
Beam width & $\sim 15^{\circ}$ & $\sim 15^{\circ}$ \\
Height range & $60-110 \mathrm{~km}$ & $70-94 \mathrm{~km}$ \\
Sampling resolutuion & $3 \mathrm{~km}$ & $2 \mathrm{~km}$ \\
Wind analysis & FCA & FCA \\
Observation since & $1978-$ today & $1990-$ today \\
\hline
\end{tabular}

olution of $3 \mathrm{~km}$. A detailed description of the MF-radar at Saskatoon can be found in Meek and Manson (1987).

All-sky meteor radars employ one antenna for transmission and a five-antenna interferometer for reception. This provides a range resolution of $2 \mathrm{~km}$ and an angular resolution of $2^{\circ}$ for meteor location. The basic construction and functionality of the MRs used in this study is nearly identical to the system originally described in Hocking et al. (2001). A summary of the characteristics of all MRs used in this study is given in Table 1.

In this study, we also investigate the day-to-day variability of the mesospheric temperature estimated from meteor fading decay times at the peak of the meteor layer at around $90 \mathrm{~km}$. Temperatures are derived by the combination of altitude variations in the meteor decay time and an empirical model of the mean temperature gradient at the peak altitude of the meteor layer (for details see Singer et al., 2003; Hocking et al., 2004; Stober et al., 2012).

The diurnal, semidiurnal and terdiurnal tides, which are obtained from least-squares fits of hourly mean winds for 4day intervals shifted by one day, were removed from the prevailing wind for our wind analysis. The estimation of PWs results from a wavelet analysis (Torrence and Compo, 1998). 


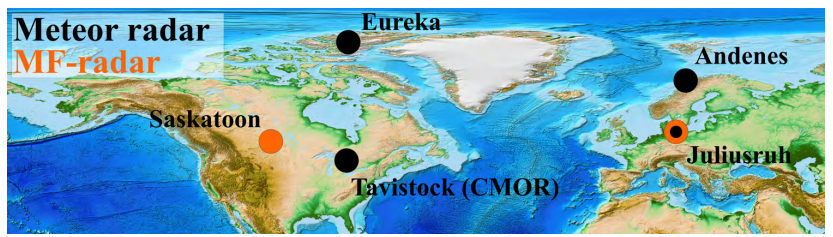

Fig. 1. Map of MR and MF-radar stations used in this study.

The calculation of the wavelet transform $W_{n}(s)$ is conducted as described in Matthias et al. (2012).

\subsection{MLS measurements}

For a global view of the temperatures and for the estimation of the wavenumber and period of PWs during SSWs, temperature and geopotential height (GPH) data from the Microwave Limb Sounder (MLS) are used. MLS is a limb scanning emission microwave radiometer on the NASA Aura satellite (Waters et al., 2006; Livesey et al., 2007). Aura was launched on 15 July 2004 into a sun-synchronous polar orbit at $705 \mathrm{~km}$ altitude with a $98^{\circ}$ inclination. The MLS instrument scans the limb in the forward direction of the orbital plane which gives a global coverage from $82^{\circ} \mathrm{S}$ to $82^{\circ} \mathrm{N}$ on each orbit. The useful height range of temperature data is approximately 8 to $97 \mathrm{~km}(316-0.001 \mathrm{hPa})$ with a vertical resolution of $\sim 4 \mathrm{~km}$ in the stratosphere and $\sim 14 \mathrm{~km}$ at the mesopause determined by the full width at half maximum (FWHM) of the averaging kernels (Livesey et al., 2007). GPH and temperature have the same height range and vertical resolution because they are linked through hydrostatic balance and gas law. Comparison of MLS measurements with pre-validated satellite observations show a bias of -2 to $2 \mathrm{~K}$ in the troposphere and stratosphere and a cold bias of $-4 \ldots-9 \mathrm{~K}$ in the mesosphere for temperature measurements. GPH observations have a bias of 50 to $150 \mathrm{~m}$ in the troposphere and stratosphere and up to $-450 \mathrm{~m}$ at $0.001 \mathrm{hPa}$ (see Froidevaux et al., 2006, and Schwartz et al., 2008).

Here we use data from the level 2 version 2.2 data product. We removed poor data by screening methodologies described by Livesey et al. (2007). The geometric altitudes are estimated from the pressure levels as follows:

$h=-7 \cdot \ln (p / 1000)$, where $h$ is the altitude in $\mathrm{km}$ and $p$ the pressure in $\mathrm{hPa}$. Note that there is a difference between geometric and geopotential heights especially in the mesosphere. However, for studies of PWs and considering the altitudinal resolution of MLS in the mesosphere, this difference is not relevant.

To estimate the period and wavenumber of a PW, a twodimensional least-squares method for spectral analysis of space-time series is used following the procedure described in Wu et al. (1995). The basic function is given by

$y_{i}=A \cos \left(2 \pi\left(f t_{i}-s \lambda_{i}\right)\right)+B \sin \left(2 \pi\left(f t_{i}-s \lambda_{i}\right)\right)$ where $A$ and $B$ are the parameters to be fitted and where $f$ is the frequency, $s$ is the wavenumber, $t_{i}$ is the time and $\lambda_{i}$ and $y_{i}$ are longitude and GPH, respectively. We note that this method has its limits on the one hand to distinguish between particular superimposed waves as discussed by Pancheva et al. (2009) and on the other hand we have to consider possible aliasing effects as discussed by Tunbridge et al. (2011). Results should therefore be interpreted carefully.

For the determination of the latitudinal and altitudinal expansion of a PW with a given wavenumber and period the following calculation is made for $5^{\circ}$ steps and at every pressure level. The maximum amplitude of a sliding window of reasonable length (4 times the length of the considered wave's period) within a given time interval over a $5^{\circ}$ latitudinal band centred around the considered latitude is calculated by using Eq. (1). Frequency/wavenumber spectra of PWs from MLS mainly show aliasing effects. These effects are discussed by Meek and Manson (2009), Tunbridge et al. (2011) and McDonald et al. (2011) for example. These aliasing effects can be neglected though, since they are mostly weaker side lobes of a "true" wave and we use the maximum amplitude in this study.

\subsection{MERRA}

For the investigation of the spatial extent of the zonal wind reversal in the stratosphere and mesosphere during the SSWs between 2006 and 2012 considered here, we use the assimilated model data from MERRA from NASA. The analysed fields of MERRA on model levels with a native grid of $\frac{1}{2}^{\circ} \times \frac{2}{3}^{\circ}$ and a $6 \mathrm{~h}$ temporal resolution are used. The vertical range of this MERRA product is 985 to $0.01 \mathrm{hPa}$, i.e. from the surface to approximately $80 \mathrm{~km}$. For further information on MERRA see Rienecker et al. (2011) and for a file specification of MERRA products see Lucchesi (2012). Comparison of MERRA with other reanalysis products and satellite measurements shows a good agreement in the stratosphere (Rienecker et al., 2011; Yoo et al., 2013). However, MERRA temperatures have a cold bias of $5 \mathrm{~K}$ above $1 \mathrm{hPa}$ compared to MLS temperatures (Rienecker et al., 2011). Thus, MERRA data in the lower mesosphere have to be considered carefully.

\section{Results}

An outstanding effect of a SSW besides stratospheric warming and mesospheric cooling, is the wind reversal in the strato- and mesosphere. Figure 2 shows the zonal wind at Andenes $\left(69^{\circ} \mathrm{N}, 16^{\circ} \mathrm{E}\right)$ and Juliusruh $\left(55^{\circ} \mathrm{N}, 13^{\circ} \mathrm{E}\right)$ at $85 \mathrm{~km}$ from MR and at $49 \mathrm{~km}$ from MERRA data centred on the central day for the SSWs in 2006, 2009, 2010 and 2012. Note that the MR at Juliusruh started to operate at a later time in 2006. Thus the zonal wind data for 2006 are substituted by the MF-radar data also located at Juliusruh. The central day for major SSWs is defined following Labitzke and Naujokat 

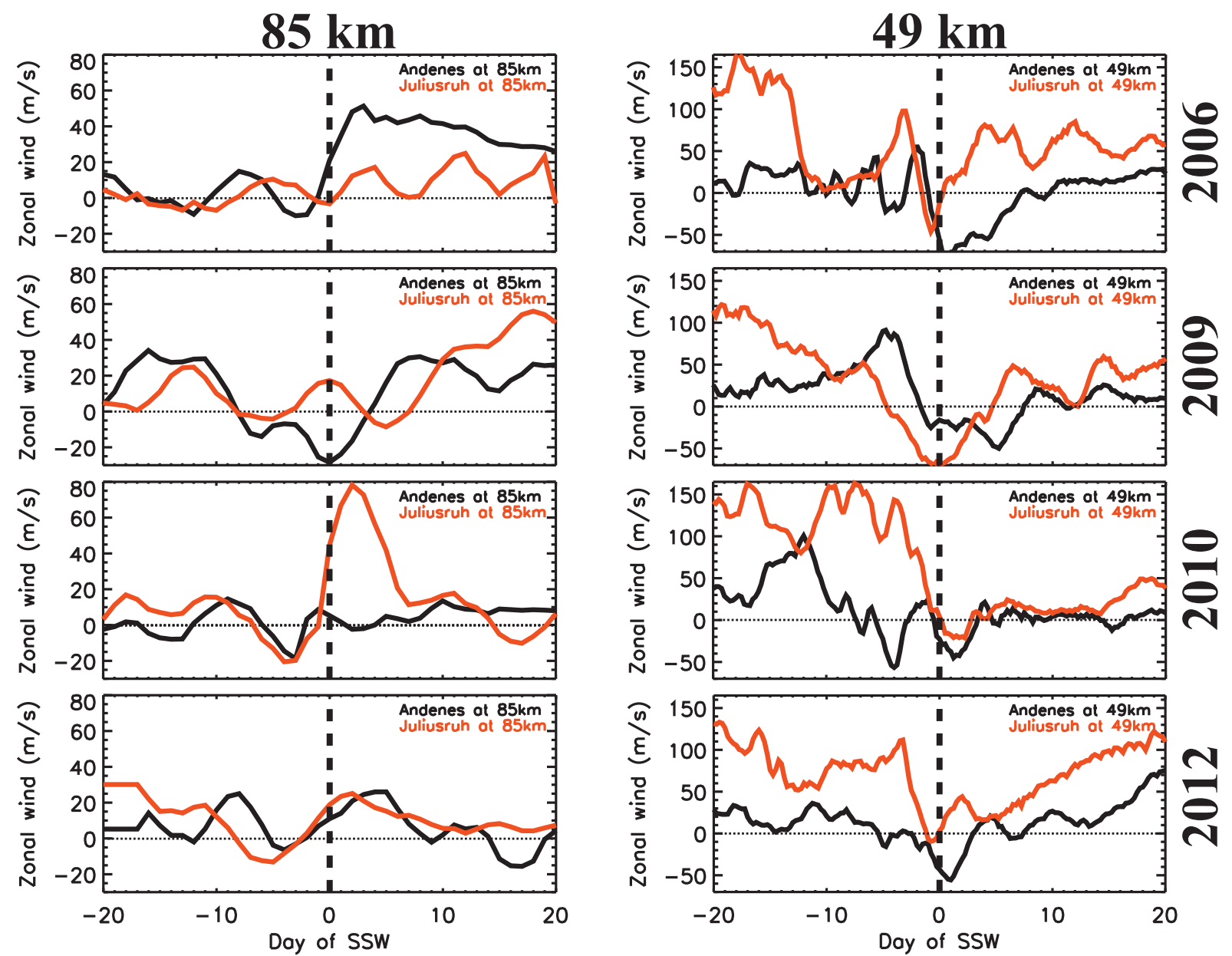

Fig. 2. Zonal wind at Andenes (black) and Juliusruh (red) at $85 \mathrm{~km}$ (left) from MR and $49 \mathrm{~km}$ (right) from MERRA data centred around the central day (black dashed line) of the respective SSW of 2006, 2009, 2010 and 2012. Terdiurnal, semidiurnal and diurnal tides were removed for the MR data.

(2000) as the day where the zonal mean zonal wind reverses $(\bar{u}<0)$ at $60^{\circ} \mathrm{N}$ at $10 \mathrm{hPa}$ and the temperature gradient between 60 and $90^{\circ} \mathrm{N}$ has its local maximum (as in Matthias et al., 2012). The central days of the major events considered here are 21 January 2006, 22 January 2009 and 28 January 2010. The central day of the minor warming 2012 is defined as the day where the zonal mean zonal wind at $60^{\circ} \mathrm{N}$ and at $10 \mathrm{hPa}$ has its minimum, i.e. the central day is $17 \mathrm{Jan}-$ uary 2012.

The mesospheric wind reversal from eastward to westward wind at $85 \mathrm{~km}$ during the SSW of 2006 occurs before the central day at Andenes and at the central day at Juliusruh whereas the maximum of the westward wind at polar is stronger than at mid-latitudes around the central day. Afterwards, Andenes shows a strong and rapid increase of the eastward wind with no significant wave activity. In contrast to Andenes occurs at Juliusruh at mesospheric altitudes a weaker eastward wind with a strong wave activity. The zonal wind at $49 \mathrm{~km}$ at both locations reverses slightly before the central day, but first at Juliusruh and a short time later at Andenes. Similarly to mesospheric altitudes the westward wind at polar appears stronger than at mid-latitudes. In contrast to mesospheric altitudes the eastward wind occurs stronger at Juliusruh after the SSW than at Andenes, but shows again a strong wave-like behaviour at mid-latitudes while at Andenes no significant wave activity is presented. This is what we consider to be a "normal" SSW with a typical latitudinal behaviour. The SSW of 2006 is representative for all "normal" events. In the following, we will therefore use this event for comparison with the other events considered here.

In contrast to 2006, the events in 2009, 2010 and 2012 show a simultaneous or even earlier wind reversal with a similar strong or even stronger westward wind at Juliusruh than at Andenes at $85 \mathrm{~km}$. The wave activity increased at $85 \mathrm{~km}$ in contrast to 2006 before and after the SSW at Juliusruh and at Andenes except for 2012 where no wave-like behaviour is considered after the SSW at Juliusruh. The onset of the wind reversal at $49 \mathrm{~km}$ varies with time, and the following 

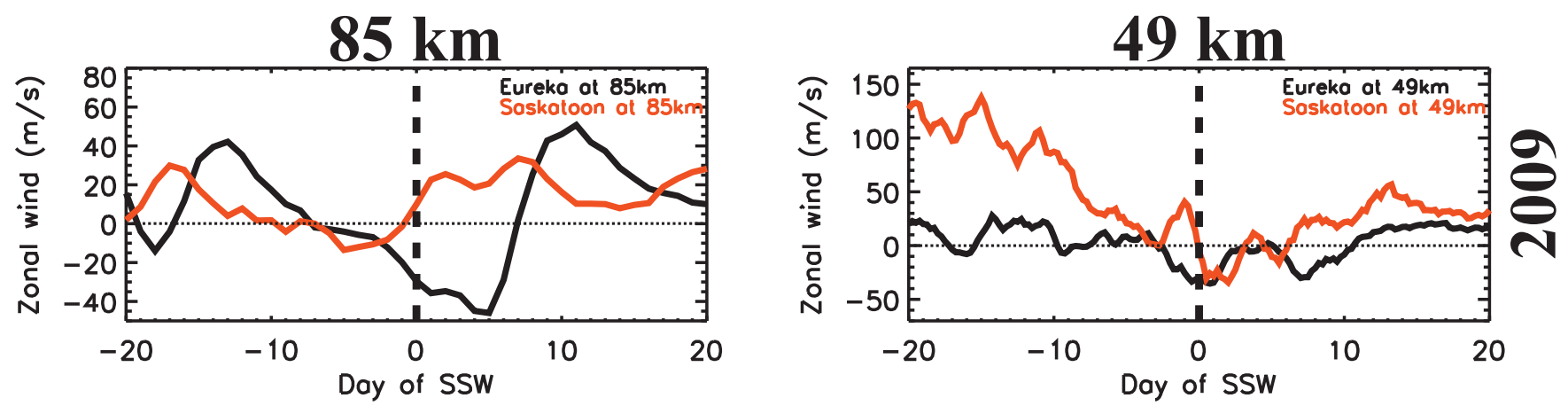

Fig. 3. Zonal wind at Eureka (black) and Saskatoon (red) at $85 \mathrm{~km}$ (left) from the respective radar data and $49 \mathrm{~km}$ (right) from MERRA data centred around the central day (black dashed line) of the SSW of 2009. Terdiurnal, semidiurnal and diurnal tides were removed from the MR and MF-radar data.

westward wind is usually as in 2006, weaker at Juliusruh than at Andenes, whereas in 2009 the westward wind appears stronger at Juliusruh than at Andenes. Also the wave activity after the events varies from year to year. While the wave activity is strong at Juliusruh and Andenes after the warming in 2009 , the stratosphere is stable with no significant wave activity at both locations in 2010 . The wave activity at $49 \mathrm{~km}$ was increased at Andenes after the event in 2009 but no significant wave activity occurred at Juliusruh. Note that zonal wind observations at both locations, i.e. Andenes and Juliusruh, are representative for the zonal wind in the Eastern Hemisphere.

As an example for the Western Hemisphere, similar to Fig. 2, Fig. 3 shows the zonal wind at Eureka $\left(80^{\circ} \mathrm{N}, 86^{\circ} \mathrm{W}\right)$ and Saskatoon $\left(52^{\circ} \mathrm{N}, 107^{\circ} \mathrm{W}\right)$ at $85 \mathrm{~km}$ from MR (Eureka) and MF-radar (Saskatoon) and at $49 \mathrm{~km}$ from MERRA data centred on the central day for the SSW in 2009. Similar to the Eastern Hemisphere (Andenes and Juliusruh) reverses the zonal wind in 2009 simultaneously at Eureka and Saskatoon at $85 \mathrm{~km}$ with a stronger and longer lasting westward wind at Eureka than at Saskatoon. Afterwards, there is a rapid and strong increase of the eastward wind with no wave-like behaviour at Eureka and a weaker eastward wind with a wavelike behaviour at Saskatoon. In contrast to the Eastern Hemisphere, the wind reversal occurs first at Eureka and 3 days later at Saskatoon at $49 \mathrm{~km}$ in 2009 and the westward wind has similar strength at both locations. Like in the Eastern Hemisphere the zonal wind has shown a wave-like behaviour at Eureka and Saskatoon after the SSW.

These results show differences in the latitudinal behaviour of the zonal wind between 2006 and the other three years considered in this study. While in 2006 the westward wind during the wind reversal occurs stronger at pole than at midlatitudes it appears similar strong or even stronger at midlatitudes than at polar latitudes especially in the mesosphere during the events in 2009, 2010 and 2012. Also the latitudinal dependence of the onset of the wind reversal differs from year-to-year. Note that besides latitudinal also longitudinal differences occur in the local measurements of the zonal wind. The longitudinal dependence of SSWs is not the main focus in this paper, but will be a matter of future investigations.

These local measurements indicate an unusual latitudinal behaviour of the SSW in 2009, 2010 and 2012 in comparison with the "normal" warming in 2006. For a more global view on the zonal wind Fig. 4 represents the zonal mean zonal wind from MERRA as a function of latitude and height 5 days before, at the corresponding central day, and 5 days after the central day of the SSWs of 2006, 2009, 2010 and 2012. Five days before the central day, all events are characterised by a weak wind reversal at the pole in the stratoand mesosphere whereas these reversals are separated by an eastward wind around 50 to $60 \mathrm{~km}$ except for 2009. In 2009 a strong eastward wind at high and mid-latitudes appears five days before the central day of the record warming.

On the central day the wind reverses from polar Mesosphere and Upper Stratosphere (hereafter: MUS) to stratospheric mid-latitudes in 2006. Hence, there is no continuous westward wind band between the pole and lower latitudes. In contrast to 2006, the other events in 2009, 2010 and 2012 show this continuous westward wind band only between the pole and lower latitudes and the wind reversal reaches from polar MUS to the lower latitude stratosphere around $20^{\circ} \mathrm{N}$.

Five days after the central day the wind reversal of the SSW of 2006 looks very similar to that on the central day but has moved downwards. This downward movement or downward progression is also observable in 2009 and 2010 in which the eastward wind in 2010 already dominates the MUS. The polar latitudes in 2012 show a strong eastward wind five days after the central day from stratosphere to mesosphere, i.e. the wind reverses back from westward to eastward. However, at mid and lower latitudes the stratosphere still shows westward wind as a result of the previous wind reversal. It seems like the wind reversal in this particular year is breaking down from the polar mesosphere to the lower latitude stratosphere. Note that there is a dependence from the selected central day, especially in 2010 where after a short wind reversal around 28 January a second one occurs 

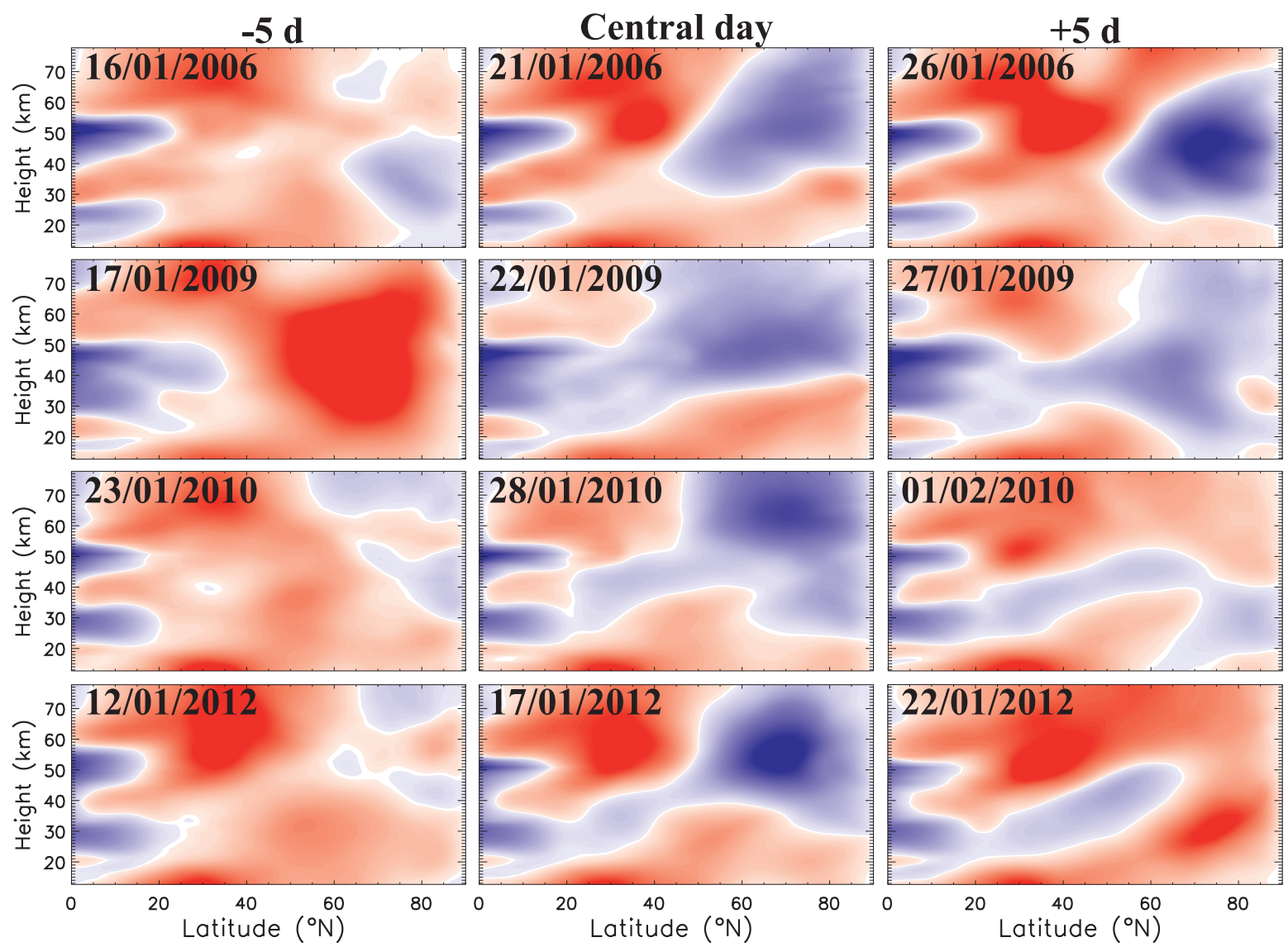

Fig. 4. Zonal mean zonal wind 5 days before, at and 5 days after the central day of the year 2006, 2009, 2010 and 2012 as a function of latitude and height from MERRA data.

which lasts much longer. Chen et al. (2012) discussed the definition of the central day for 2010 and rescheduled the central day on 2 February 2010.

Apart from the zonal wind characteristics around SSWs, the latitudinal and altitudinal temperature structure must also be considered. Figures $5 \mathrm{a}$ and $5 \mathrm{~b}$ show the daily mean zonal mean MLS temperature at 20, 40,59 and $81 \mathrm{~km}$ as a function of time and latitude for 2006 and 2009 in Fig. 5a and for 2010 and 2012 in Fig. 5b. The white dashed line marks the central day of the corresponding SSW. In the following, each altitude from bottom to top will be described separately for all years, i.e. Figs. $5 \mathrm{a}$ and $5 \mathrm{~b}$ will be considered together for each height.

In 2006, 2009 and 2010 a long lasting warming occurs from pole to mid-latitudes at $20 \mathrm{~km}$ after the central day. While in 2009 and 2010 this warming reaches down to around $50^{\circ} \mathrm{N}$, in 2006 , with a typical polar behaviour, it is observable only down to $60^{\circ} \mathrm{N}$. Note that in 2010 the warming did not start directly after the central day but $\sim 15$ days later. The cause for this time shift might be the temporal development of the zonal wind in 2010 as discussed before. The rescheduled central day by Chen et al. (2012) on 2 February 2010 is in a good agreement with the warming at $20 \mathrm{~km}$ observed here. During the minor warming of 2012 a warming also occurs after the central day at $20 \mathrm{~km}$, but in contrast to those in 2006, 2009 and 2010 it is observed between 50 and $70^{\circ} \mathrm{N}$ and not at the pole. This extraordinary behaviour will be further investigated in the discussion (see Sect. 4).

At $40 \mathrm{~km}$ warmings occur during all events considered in this study. The temperature peaks around the central day from pole to $\sim 60^{\circ} \mathrm{N}$ during every SSW. After these warmings a temperature increase occurs between $20^{\circ}$ and $40^{\circ} \mathrm{N}$. This indicates an equatorward progression of the warming in the stratosphere around $40 \mathrm{~km}$ which can be influenced from the mean meridional residual circulation.

However, there is no latitudinal difference of the temperature during the warming between the typical polar behaviour in 2006 and the more mid-low-latitudinal behaviour in 2009, 2010 and 2012. But the comparison of the temperature at mid-latitudes around $50^{\circ} \mathrm{N}$ at $40 \mathrm{~km}$ before the warmings shows much higher temperatures in 2006 than in the other years considered here. While in 2006 the cold polar temperatures before the warming reach down to $60^{\circ} \mathrm{N}$, they are also observed down to $40^{\circ}$ and $50^{\circ} \mathrm{N}$ during the SSWs of 2009 , 2010 and 2012. 


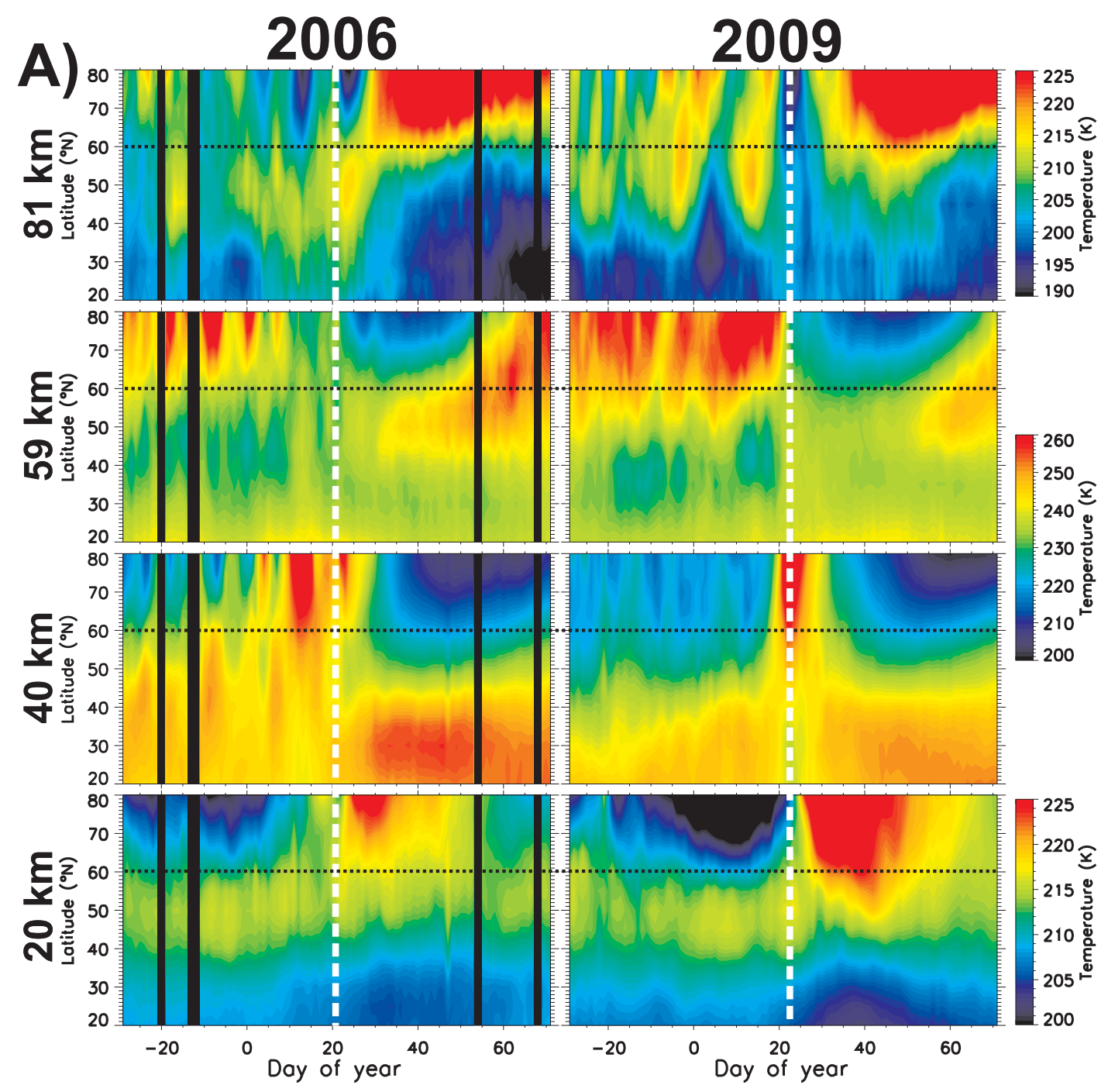

Fig. 5a. Zonal mean temperature at 20, 40,59 and $81 \mathrm{~km}$ from MLS for the winter 2005/06 and 2008/09. The vertical white dashed line marks the central day of the respective SSW and the horizonal black dashed line at $60^{\circ} \mathrm{N}$ is used for help of orientation.

The mesospheric temperature at $59 \mathrm{~km}$ shows a polar cooling after the corresponding central days which varies in length of time and strength. At the same time of the maximum of the polar cooling a warming around $50^{\circ} \mathrm{N}$ occurs and spreads out to the pole with time. The polar and midlatitude mesospheric temperatures before the SSWs are very variable due to increased PW activity and more stable afterwards due to the decreased PW activity after SSWs (see for example Matthias et al., 2012).

The mesospheric cooling at $80 \mathrm{~km}$ is more narrow during all considered events than at $59 \mathrm{~km}$ and occurs around the central day and not afterwards as it is the case at $59 \mathrm{~km}$. After this cooling a strong warming occurs at polar latitudes whereas this warming appears weaker in 2010 and 2012 than in 2006 and 2009. The polar mesosphere before the SSW in all cases is very variable. This can be also attributed to the increased PW activity. During the SSW of 2006 a strong warm- ing occurs between $40^{\circ}$ and $55^{\circ} \mathrm{N}$ at $80 \mathrm{~km}$ simultaneous to the polar cooling. Similar observations are obtained in 2010 and 2012 whereas the warming in 2010 appears much weaker and in 2012 slightly before the central day. It seems that this phenomenon occurs only during vortex displacement events and not during splitting events like in 2009 where the mesosphere shows cold temperatures at all latitudes during the SSW.

Independent of the the latitudinal variations of the temperature we found a downward progression from mesosphere to stratosphere during all events. Such a downward movement was previously mentioned in connection with the zonal wind reversal. Here, the mesospheric cooling first occurs at $81 \mathrm{~km}$ and then moves downward to the lower mesosphere around $59 \mathrm{~km}$ where it also lasts much longer. This downward movement can also be continued to stratospheric altitudes around $40 \mathrm{~km}$ where after the warming the temperature 


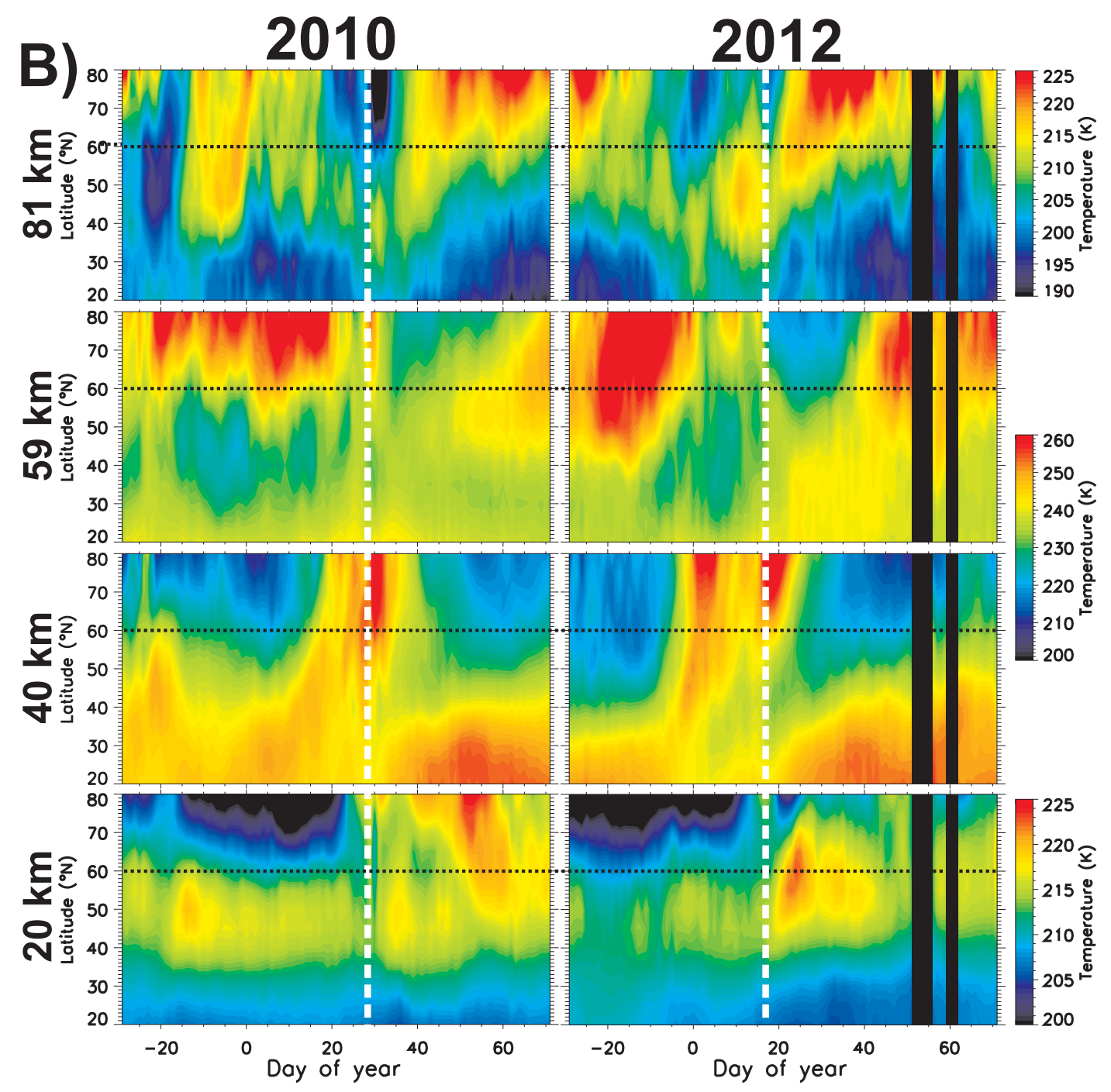

Fig. 5b. Same as Fig. 5a just for the winter 2009/10 and 2011/12.

again decreases to a typical polar stratospheric level. However, this cooling occurs later as in the lower mesosphere at $59 \mathrm{~km}$ and thus there is a downward movement of the mesospheric cooling to stratospheric heights. A similar behaviour can be observed in the stratosphere. The warming at $40 \mathrm{~km}$ occurs around the central day while the warming at $20 \mathrm{~km}$ appears afterwards and lasts much longer. Note that this downward movement of the cooling/warming during SSWs is consistent with the downward progression of the wind reversal as discussed by Hoffmann et al. (2007) and found in the composite analysis of Matthias et al. (2012).

Summarising the temperature characteristics around SSWs it is to be said that we did not find a continuous band of warm/cold temperatures in the stratosphere/mesosphere between the pole and lower latitudes as in the zonal wind. Nevertheless, the exceptional SSWs in 2009, 2010 and 2012 (with a continuous westward wind band between pole and lower latitudes) show differences in temperatures between $35^{\circ}$ and $60^{\circ} \mathrm{N}$ in the strato- and mesosphere before and after the central day of the warmings compared to the polar dominated event in 2006. Besides the stratospheric equatorward movement of the warming, we also observed a downward progression of the stratospheric warming and mesospheric cooling during all events.

The previously mentioned mid-latitudinal mesospheric warming that occurs in the zonal mean MLS temperature data during vortex displacement events will be considered more closely in the following.

Figure 6 shows the relative temperature variations from meteor radar data at approximately $90 \mathrm{~km}$ for the years 2009 , 2010 and 2012 from radar stations at Andenes $\left(69^{\circ} \mathrm{N}, 16^{\circ} \mathrm{E}\right)$ and Juliusruh $\left(55^{\circ} \mathrm{N}, 13^{\circ} \mathrm{E}\right)$ for the Eastern Hemisphere and Tavistock (Canadian Meteor Orbit Radar, short: CMOR, $\left.\left(43^{\circ} \mathrm{N}, 81^{\circ} \mathrm{W}\right)\right)$ for the Western Hemisphere. Note that the 


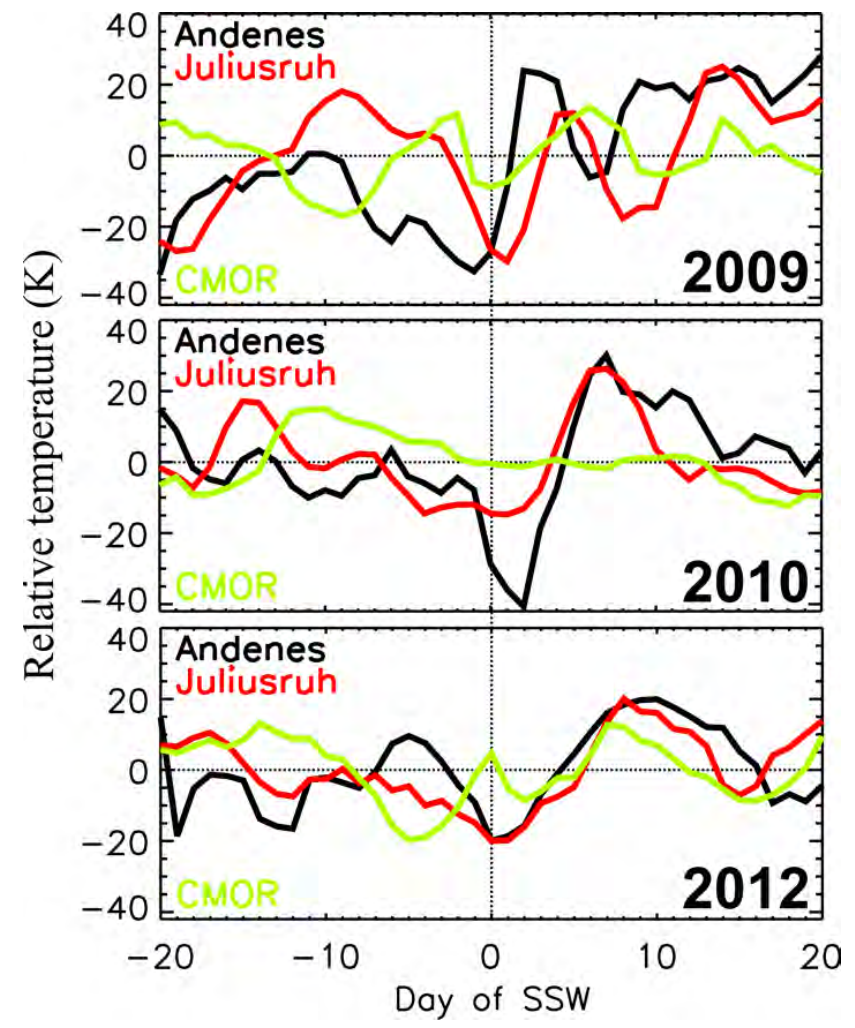

Fig. 6. Relative temperature from $M R$ at $\sim 90 \mathrm{~km}$ at Andenes, Juliusruh and Tavistock (CMOR) centred around the central day of the respective SSW. The black dashed line marks the central day.

year 2006 is missing because the MR was only installed at Juliusruh later in the year. In addition, there is no meteor radar at Saskatoon so that we use the CMOR data instead as a substitution for mid-latitudinal Western Hemisphere measurements. The relative temperature is centred on the central day of the respective warming which is marked as a black dashed line. Note that meteor radar temperatures depend on the assumption of an empirical temperature gradient model. Therefore, we subtracted the mean temperature of the observation period from each temperature profile and concentrate on the day-to-day variability and on the tendency of each single temperature curve in this study.

During the record warming of 2009 all 3 locations show a temperature decrease around the warming as it was observed in the zonal mean temperatures from MLS in Figs. 5a and 5b. In 2010 there is a strong cooling at Andenes (polar latitudes) while a weak cooling is observed at Juliusruh (midlatitudes). However, the western hemispheric mid-latitudinal CMOR radar shows no significant cooling in connection with the SSW. The minor warming in 2012 splits the hemispheres. While the polar and the mid-latitudinal temperature decrease in the Eastern Hemisphere, the mesospheric temperature in the mid-latitudinal Western Hemisphere increases. Thus Fig. 6 indicates that the mesospheric mid-latitudinal warming in Figs. 5a and 5b depends on the longitudinal location.

To understand the differences between local measurements and zonal mean temperature observations at mesospheric mid-latitudes during SSWs, Fig. 7 shows the projection of MLS temperatures at $81 \mathrm{~km}$ at the corresponding central day for the events considered in this study. The white points mark the location of the local measurements in Fig. 6. Note that the meteor temperatures of Fig. 6 are observed around $90 \mathrm{~km}$ and the MLS temperatures at $81 \mathrm{~km}$ with a vertical resolution of $10 \mathrm{~km}$. So there is an altitudinal discrepancy that should be regarded. During all events considered here Andenes and Juliusruh lie in the cold part of the global temperature pattern which leads to the decreasing temperatures of Fig. 6. In contrast, the CMOR radar is mostly located at the much warmer part of the temperature pattern with the exception of 2009 where it is located between the cold and the warm part of the global temperature pattern. Thus the measured temperatures strongly depend on their location relative to the global temperature pattern. From this it follows that zonal mean values should be considered very critically, especially for comparison with local measurements. A possible reason for the mesospheric mid-latitudinal warming is discussed in Sect. 4.

Our hypothesis is that the reason for the continuous westward wind band from the pole to lower latitudes and the temperature changes at mid- and lower latitudes is the increased PW activity at the same latitudes. Therefore, the next Fig. 8 shows the wavelet spectrum of the meridional wind at $85 \mathrm{~km}$ for the winter 2008/09 at the different considered locations. The vertical black dashed line marks the central day of the SSW in 2009. The dominating waves around the warming at all locations except for Saskatoon are a 10-day (period: 8-12 d) and/or a 16-day wave (period: $12-20 \mathrm{~d}$ ) as also mentioned by Matthias et al. (2012). Another wave that occurs around the warming is a 6-day wave (period: 5-7 d). Beside these waves also 2- and 3-day waves occur but their direct relation to SSWs is beyond the scope of this paper.

With the help of MLS geopotential height data, we found that all waves in all years have a wavenumber between -1 and 1, i.e. westward or eastward propagating (not shown, see also Matthias et al., 2012). Our main interest focuses on the latitudinal behaviour of PWs responsible for the latitudinal variability of SSW effects. Therefore, Fig. 9 shows the amplitude of the 6-day, 10-day and 16-day wave with wavenumbers between -1 and 1 as a function of latitude and height for the four considered winters from MLS geopotential height data. The amplitude is calculated as the maximum amplitude of a sliding window of 24 days for the 6-day wave, of 40 days for the 10-day wave and of 70 days for the 16-day wave at each latitude and height between day 335 of the previous year and day 60 of the actual year. The 6-day wave has its maximum at polar latitudes in the MUS and extends as far as south as $50^{\circ} \mathrm{N}$ in every year. However, the 10 -day wave shows an increased activity to as far south as $30^{\circ} \mathrm{N}$ except for 2006, i.e. 

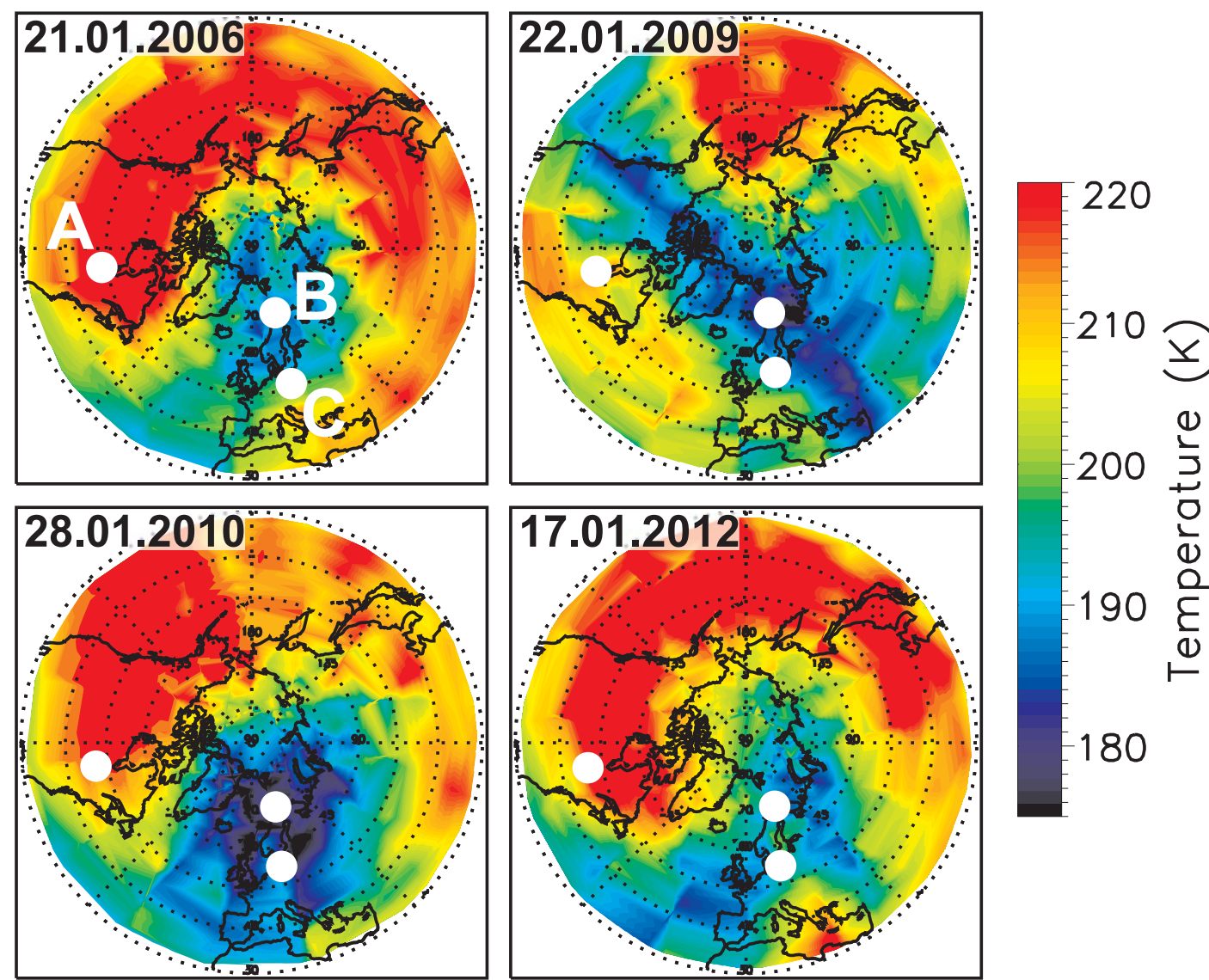

Fig. 7. Projection of the MLS temperature data at $81 \mathrm{~km}$ over the Northern Hemisphere of the central day of the respective SSW, i.e. each projection shows the same day as in Fig. 6 the dashed line for the respective year. The white points mark the local meteor temperature measurements for (A) Tavistock, (B) Andenes and (C) Juliusruh.

the SSW without the continuous westward wind band from the pole to the subtropics.

Maximum amplitudes are found at the pole in all considered winters. However, in 2009 for example, there is a second smaller maximum of the 10-day wave activity at $50^{\circ} \mathrm{N}$ which reaches also down to $30^{\circ} \mathrm{N}$. The 10-day wave activity in 2010 and 2012 is very similar. Both years show an increased wave activity in the MUS from the pole as far as south as $30^{\circ} \mathrm{N}$. The 16-day wave shows a strong increased activity between $40^{\circ}$ and $80^{\circ} \mathrm{N}$ in 2010 while in 2009 and 2012 the 16-day wave occurs only at polar latitudes. In 2006 the 16day wave also appears at polar and mid-latitudes down to $50^{\circ} \mathrm{N}$ but is very weak compared to the 6- and 10-day wave during this winter and therefore less important for this warming. Thus the transient PWs show an increased wave activity between $30^{\circ}$ and $50^{\circ} \mathrm{N}$ around the exceptional warmings that does not occur in the polar dominated year 2006.

It is well accepted that the temporal development of stationary waves is responsible for the occurrence of SSW (Charlton and Polvani, 2007). Figure 10 shows the latitudinal structure of the amplitude of the stationary wave 1 of the SSWs considered in this study expect for 2009 which was a splitting event (see Manney et al., 2009), and therefore the dominating stationary wave 2 is presented. The amplitude of the stationary geopotential height wave from MLS data is shown as a function of latitude and height. The left column displays the amplitude 5 days before the central day, the middle one at the central day and the right column 5 days after the central day.

Five days before every central day considered in this study an increased stationary wave 1 activity occurs from the pole to around $45^{\circ}$ to $50^{\circ} \mathrm{N}$. Only the maximum amplitude of the stationary wave 2 in 2009 shows an increased activity from $35^{\circ}$ to $75^{\circ} \mathrm{N}$ and not at the pole like in the other events. At the central day, the normal polar dominated SSW in 2006 shows an increased activity again from pole to mid-latitudes while in the other three events a clear increased activity down to $30^{\circ} \mathrm{N}$ is observed. Five days after the central day the amplitudes decrease in every event. At this point the warming in 2006 also shows an increased activity in the lower latitude mesosphere but with a much weaker amplitude compared to that before and at the central day. The other events basically show the same behaviour as at the central day but with weaker amplitudes. Only in 2010 a third maximum occurs 


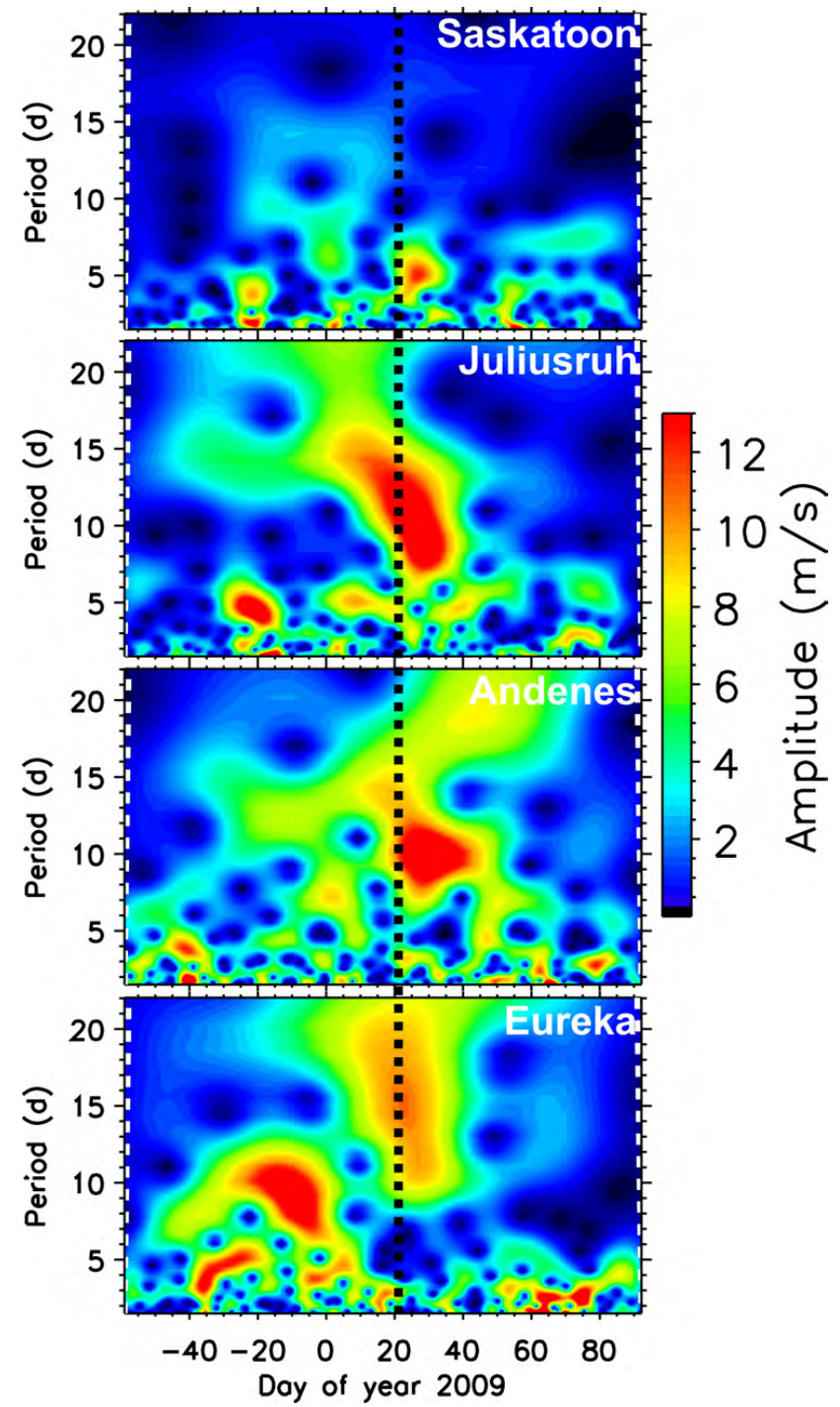

Fig. 8. Wavelet spectrum of the meridional wind at $85 \mathrm{~km}$ at different locations for winter 2008/09 from the respective MF and MR systems. The black dashed line marks the central day of the SSW and the white dashed lines at the edge represent the cone of influence.

above the other two in the upper mesosphere/lower thermosphere. Thus transient and stationary PWs show an increased wave activity between $30^{\circ}$ and $50^{\circ} \mathrm{N}$ during the displaced warmings in 2009, 2010 and 2012.

To understand the differences in the stationary wave activity between the events considered here, we examine the three-dimensional wave activity fluxes for quasi-geostrophic stationary waves following Plumb (1985, Eq. 7.1). The wave flux vector $\boldsymbol{F}$ is a three-dimensional vector depending on the longitude $\lambda$, the latitude $\varphi$ and on the height $z$.

Figure 11a) shows the wave flux activity vectors from MERRA as a function of longitude and latitude averaged between $25 \mathrm{~km}$ and $50 \mathrm{~km}$ for a 5 day mean after the corre- sponding central day of each SSW considered in this study. The coloured background represents the flux divergence, i.e. red coloured regions are sources of stationary PW flux and blue coloured regions are sinks. During the SSW of 2006, the flux vectors indicate wave 1 structure between $60^{\circ} \mathrm{N}$ and the pole. Below $60^{\circ} \mathrm{N}$ between $50^{\circ} \mathrm{E}$ and $50^{\circ} \mathrm{W}$ the flux vectors are equatorward directed but decrease rapidly below $30^{\circ} \mathrm{N}$. Around the zero meridian between 60 and $80^{\circ} \mathrm{N}$ occurs a big source of wave flux with 2 smaller arms between 40 and $60^{\circ} \mathrm{N}$. Sources and sinks alternate with a light eastward shift from pole to $20^{\circ} \mathrm{N}$.

The vortex splitting event 2009 shows a wave 2 structure symmetric around $60^{\circ} \mathrm{N}$ with an equatorward flux around $100^{\circ} \mathrm{E}$ and $100^{\circ} \mathrm{W}$. This is also the region where the sources and sinks alternate equatorward with a light eastward shift, but there is an additionally longitudinal variation.

The flux vector structures of the events in 2010 and 2012 are very similar whereas the intensity is stronger in 2010 than in 2012. Both events show two stripe pattern of equatorward movement. The weaker one occurs between $40^{\circ} \mathrm{N}$ and $80^{\circ} \mathrm{N}$ and between $100^{\circ} \mathrm{W}$ and the zero meridian. The second stronger stripe pattern is shifted parallel to the first one and occurs between $70^{\circ} \mathrm{N}$ and $30^{\circ} \mathrm{N}$ and between $50^{\circ} \mathrm{W}$ and $90^{\circ} \mathrm{E}$. These stripe pattern are also visible in the alternation of the sources and sinks which goes as before equatorward with a light eastward shift and are stronger in 2010 than in 2012 too. In comparison to 2006 these equatorward fluxes are stronger and reach from polar to subtropical latitudes which is in contrast to the downward flux in 2006 which starts at $60^{\circ} \mathrm{N}$.

Figure $11 \mathrm{~b}$ shows the zonally averaged wave flux activity vectors as a function of latitude and height for a 30 day mean before the corresponding central day of 2006, 2009, 2010 and 2012. All events studied here show strictly poleward flux until $40^{\circ} \mathrm{N}$ which passes into a strictly upward flux around the pole. Only the vortex splitting event in 2009 shows a poleward flux almost until $80^{\circ} \mathrm{N}$ and therefore passes much later into the upward flux.

We summarise that the differences in the zonal wind and temperature behaviour between the normal polar dominated SSW in 2006 and the southward displaced SSWs in 2009, 2010 and 2012 are accompanied by the unusual increased PW activity (stationary and transient) at latitudes between $30^{\circ} \mathrm{N}$ and $50^{\circ} \mathrm{N}$ and the changed stratospheric dynamics during the three exceptional SSWs.

\section{Discussion}

In the following the impact of the latitudinal behaviour of PWs on the latitudinal variability of SSW effects like the zonal wind reversal and temperature changes will be discussed.

This study shows 3 exceptional SSW events with respect to their latitudinal structure within a short period (2009-2012). 


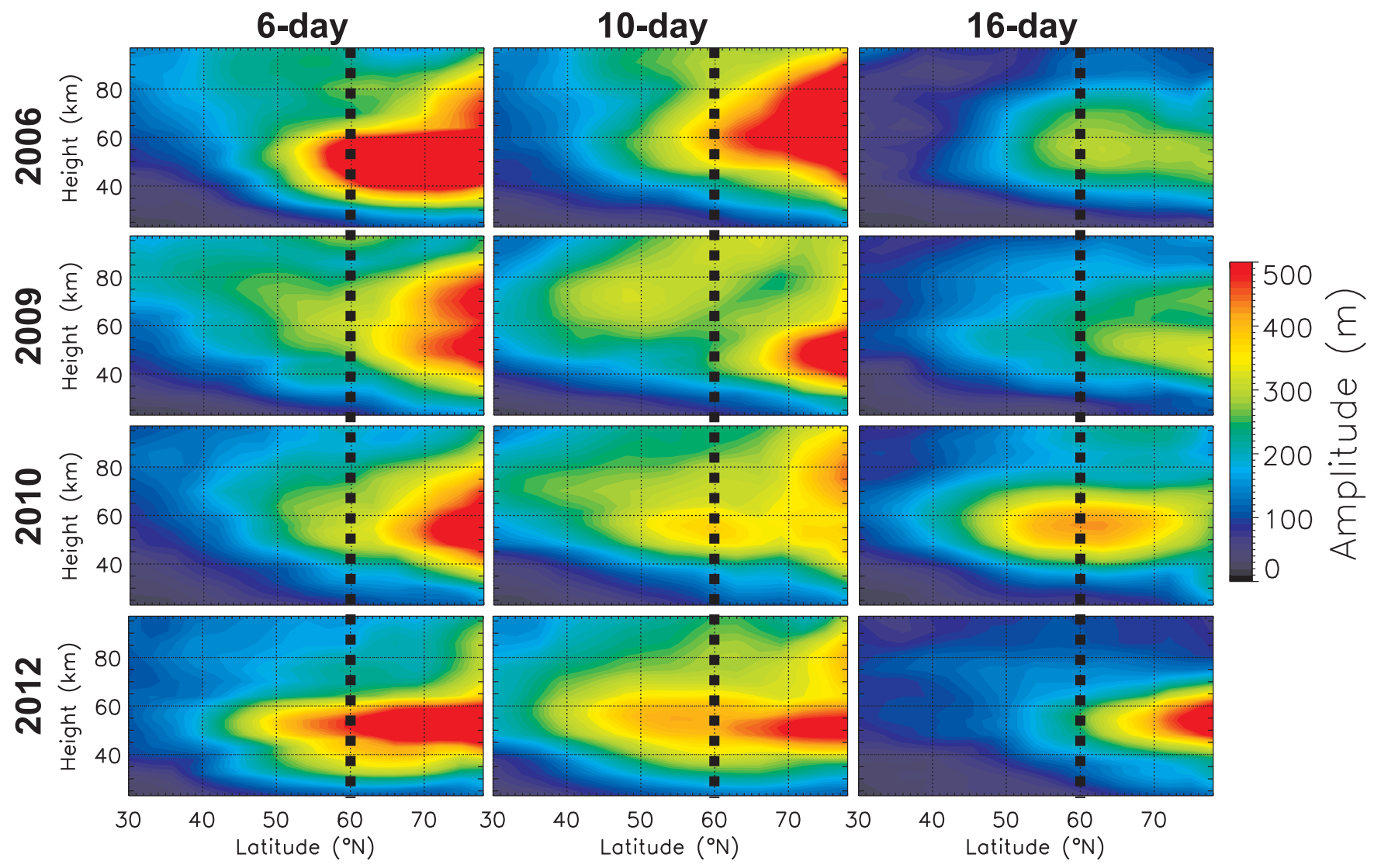

Fig. 9. Amplitude of the 6-day (period: 5-7 d), 10-day (period: 8-12 d) and 16-day (period: 12-20 d) wave from MLS geopotential. Amplitude is calculated by the maximum of a sliding window of 24/40/70 days shifted by one day between day 335 of the previous year and day 60 of the actual year. The dashed line at $60^{\circ} \mathrm{N}$ is used for the help of orientation.

That these three events are exceptions shows the composite analysis of 39 major and minor warmings between 1958 and 2001 from NCEP-NCAR reanalysis data of Limpasuvan et al. (2004). They found no evidence for a continuous westward wind band between the pole and $20^{\circ} \mathrm{N}$ in the average behaviour of a warming in the lower stratosphere up to $32 \mathrm{~km}$. This polar activity of SSW effects without a continuous westward wind band from the pole to lower latitudes is also observed in case studies for individual events, as for example in Hoffmann et al. (2007) and especially in Mukhtarov et al. (2007). Therefore, the events studied here are exceptional even if they occur in a temporally short interval.

Our observations of a continuous westward wind band from the pole to the subtropics and an occasionally stronger westward wind at mid- than at polar latitudes are corroborated by case studies of the SSW in 2010 by Chen et al. (2012) using MLS gradient winds and by Stober et al. (2012) using local radar measurements at $55^{\circ} \mathrm{N}$. However, composite analysis of Charlton and Polvani (2007) with NCEPNCAR and ECMWF re-analysis data show no continuous westward wind band between $20^{\circ} \mathrm{N}$ and the pole neither during vortex displacement events nor during splitting events. Only the vortex splitting events show an increased PW ac- tivity and westward wind down to $30^{\circ} \mathrm{N}$ which is consistent with the 2009 splitting event considered in this study. A possible explanation for the continuous westward wind band during the events in 2009, 2010 and 2012 is given in Fig. 11a. The stationary wave flux vectors, where the continuous wind band occurs, show an equatorward movement from polar to subtropical latitudes in 2009, 2010 and 2012 during the five days after the central day, but in 2006 only an equatorward movement from mid- to subtropical latitudes. Therefore, it is possible that the reversed westward wind from polar latitudes is carried down from the stationary wave flux to $20^{\circ} \mathrm{N}$ in the three displaced SSWs.

This equatorward movement of the stationary wave flux is also considered as responsible for the southward spread of the warming at $20 \mathrm{~km}$ in 2009, 2010 and 2012 in Figs. 5a and 5 b. Additionally, we observed another unusual latitudinal effect during the SSW in 2012. The warming occurs in 2012 at $20 \mathrm{~km}$ between $45^{\circ} \mathrm{N}$ and $75^{\circ} \mathrm{N}$ but not at the pole like in the other events considered here (see Figs. 5a and 5b). Therefore Fig. 12 shows the projection of the temperature from MERRA at $20 \mathrm{~km}$ in the Northern Hemisphere five days after the central day of the respective SSWs in 2006, 2009, 2010 and 2012. The cold part of the global temperature pattern 

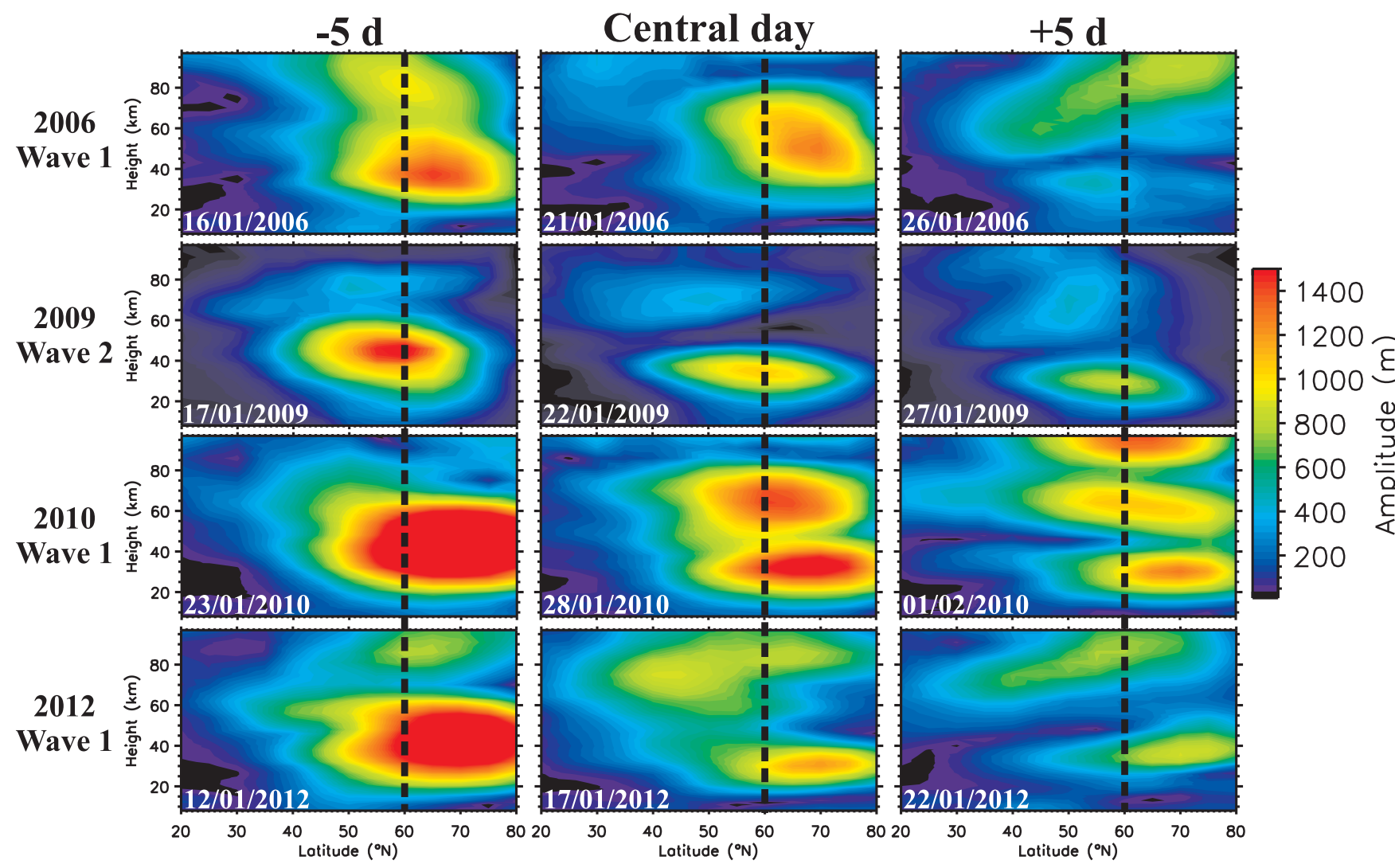

Fig. 10. Amplitude of the respective dominating stationary wave of SSW events of 2006, 2009, 2010 and 2012 as a function of latitude and height 5 days before, at the central day and 5 days afterwards. Geopotential height data are obtained from MLS. The vertical dashed line at $60^{\circ} \mathrm{N}$ is used for the help of orientation.

five days after the central day of the events in 2006, 2009 and 2010 is located between $45^{\circ} \mathrm{W}$ and $90^{\circ} \mathrm{E}$ but not on the pole. In contrast to this, the cold part of the temperature pattern in 2012 also lies between $45^{\circ} \mathrm{W}$ and $90^{\circ} \mathrm{E}$ but is rotated by $90^{\circ}$ about the longitudinal axis and is located partly on the pole. This rotation occurs only in the lower stratosphere. At upper heights such rotations are not observable. The reason for this unusual rotation of the cold temperature pattern after the SSW in the lower stratosphere in 2012 is unclear and should be further investigated.

A distinctive cooler upper stratosphere occurs around $40 \mathrm{~km}$ between $40^{\circ}$ and $60^{\circ} \mathrm{N}$ before the SSWs of 2009 , 2010 and 2012 compared to that in 2006. Similar observations have been made by Orsolini et al. (2010). The aim of their paper was to show that mesospheric $\mathrm{H}_{2} \mathrm{O}$ and temperature measurements from the Odin satellite allow to distinguish between the formation of an elevated stratopause and the descent of dry mesospheric air into the polar stratosphere. Nevertheless, Orsolini et al. (2010) show among other things the temperature from Odin between July 2001 and July 2009 as a function of latitude at $1 \mathrm{hPa}$. During the winter months the cold polar and mid-latitudinal stratospheric temperatures vary from year to year with respect to their latitudinal ex- tension. During some years, the cold temperatures reach as far south as $30^{\circ} \mathrm{N}$ as in 2009 , but during other years, for example in 2006, cold temperatures are present only up to $50^{\circ} \mathrm{N}$. Note that there is an altitudinal difference between our study and Orsolini et al. (2010) which explains the latitudinal differences in the cold temperatures. Comparisons of the stationary wave fluxes in Fig. 11b) between 2006 and the other three events show no significant differences which could explain the cold temperatures between $40^{\circ}$ and $60^{\circ} \mathrm{N}$ before central days of the SSWs of 2009, 2010 and 2012. Since PWs draw their energy from the temperature difference between the cold polar and the warm lower latitudes, we ask the question: Do the cold stratospheric temperatures at mid-low latitudes occur due to the southward extended PW activity or is the PW activity increased at lower latitudes due to the cooler temperatures at mid-low latitudes? The answer is much more complicated than the question suggests. PWs are influenced by tropical phenomena like the QBO as for example discussed in Chen and Huang (1999). Labitzke (2004) even shows a statistical relation of SSW on the QBO and on the solar cycle, but the results for the SSW of 2009 did not fit with this statistical relation (Labitzke and Kunze, 2009). In our case, the normal SSW in 2006 lies on the westerly 

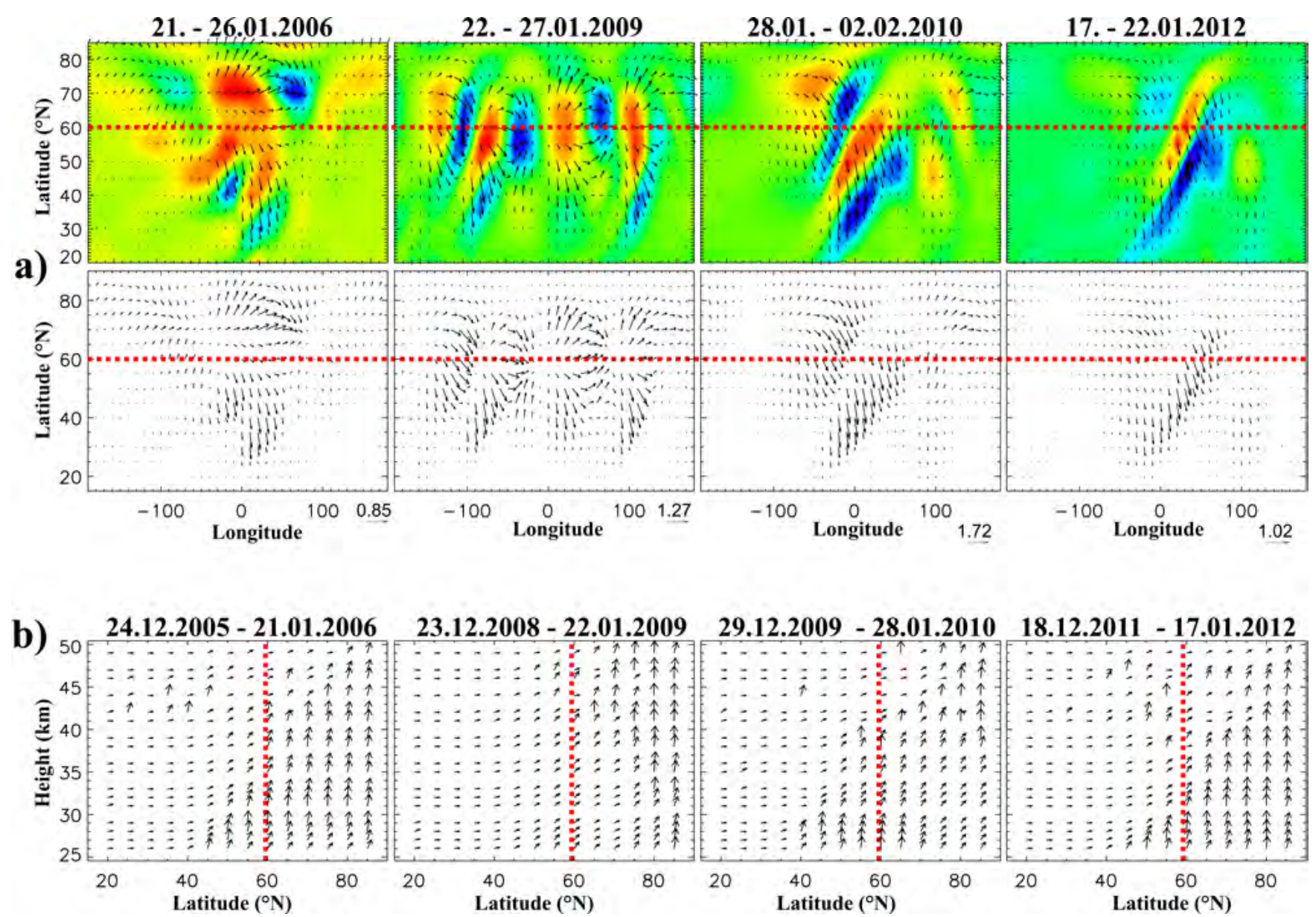

Fig. 11. Stationary wave activity flux vectors following Plumb (1985) of each SSW considered in this study (a) of a five day mean after the central day averaged over the height range between 25 and $50 \mathrm{~km}$, where the coloured background represents the flux divergence (red: source, blue: sink); top with flux divergence, bottom without (better view on the arrows) and (b) of a 30 day mean before each corresponding central day zonally averaged and scaled by $\left(F_{\varphi}, F_{\mathrm{Z}}\right) \rightarrow\left(p / p_{0}\right)^{(-1 / 2)}\left(F_{\varphi}, 100 \cdot F_{\mathrm{Z}}\right)$. Fluxes had been calculated using MERRA data provided by NASA GMAO.

phase of the QBO while the other displaced SSWs lie on the easterly phase in the hight region between 25 and $50 \mathrm{~km}$ where the continuous westward wind band occurs (see http: //www.geo.fu-berlin.de/en/met/ag/strat/produkte/qbo). Naito and Yoden (2006) studied the PW activity before and after SSWs depending on the phase of the QBO by a numerical model. They found that the dominant zone of the upward and equatorward Eliassen-Palm flux in the lower stratosphere is shifted southward in the westerly phase and poleward in the easterly phase of the QBO during a SSW. This result agrees to our observations of the Plumb flux averaged between 25 and $50 \mathrm{~km}$ (see Fig. 11), where we found an equatorward flux from pole to lower latitudes during the displaced SSW events. So there might be a connection between the QBO phase and the latitudinal displacement of SSWs but needs further investigation to approve this result. However, the reason for the cold stratospheric temperatures before the exceptional warmings at mid- and lower latitudes down to $30^{\circ} \mathrm{N}$, which are connected with an increased PW activity between $30^{\circ}$ and $50^{\circ} \mathrm{N}$, is still unclear.

The previously closer investigated mesospheric warming between $40^{\circ}$ and $60^{\circ} \mathrm{N}$ around the central day (see Figs. 5a and $5 \mathrm{~b}$ ) occurs during all vortex displacement events. From local meteor radar temperatures and global temperature maps we found distinctive longitudinal variations in the temperature at mid-latitudes depending on their location relative to the disturbed polar vortex and therefore on the phasing of PWs. Comparisons of the mesospheric temperature structure at mid-latitudes (Figs. 5a and 5b) with the stationary wave occurrence in Fig. 10 show an increased stationary wave 1 activity in the mid-latitudinal mesosphere during 2006 and 2012 around the warming and 2010 afterwards. This indicates that the increased mesospheric stationary wave activity at mid-latitudes is responsible for the mid-latitudinal mesospheric warming. 


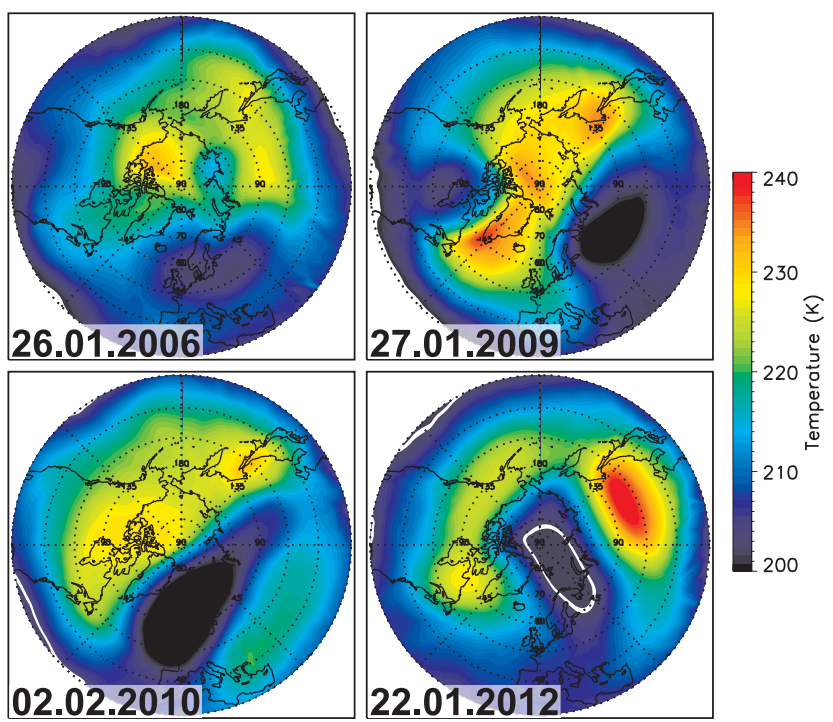

Fig. 12. Projection of the MERRA temperature data at $20 \mathrm{~km}$ over the Northern Hemisphere 5 days after the central day of the respective SSW.

Besides the latitudinal differences between the 3 displaced events and 2006, we found an equatorward movement of the warming in the stratosphere at $40 \mathrm{~km}$ during all considered events. Besides mesospheric variability in the tropics which are correlative in time with the SSW observed at higher latitudes, Shepherd et al. (2007) found a warming at stratospheric altitudes too. They explain the mesospheric variability with an increased PW activity in the mesosphere. Thus, we speculate that the stratospheric tropical warming observed here after the SSW occurs due to the enhanced PW activity not only in the mesosphere but also in the stratosphere at lower latitudes.

We summarise that the differences in the zonal wind and temperature behaviour between the normal polar dominated SSW in 2006 and the southward displaced SSWs in 2009, 2010 and 2012 are connected to the increased PW activity (stationary and transient) between $30^{\circ} \mathrm{N}$ and $50^{\circ} \mathrm{N}$ and the changed stratospheric dynamics during the three displaced SSWs.

During this study, we could not find a reason for the southward extended PW activity during the displaced SSWs of 2009, 2010 and 2012. Our hypothesis is that during the generation of PWs in the troposphere a large scale disturbance is responsible for the southward extension of the PW activity.

\section{Conclusions}

MF- and meteor radar winds at selected locations, global satellite measurements and assimilated model data have been used to investigate the impact of PWs on the latitudinal displacement of SSWs. A comparison was shown of the latitudinal structure of the zonal wind, temperature, PW activity and stationary wave flux between the normal polar dominated SSW in 2006 and the southward displaced SSWs in 2009, 2010 and 2012. The continuous westward wind band between the pole and $20^{\circ} \mathrm{N}$ as well as the southward spread warming in the stratosphere during the three exceptional warmings occur due to the equatorward stationary wave flux from polar latitudes to $30^{\circ} \mathrm{N}$.

The cold stratospheric temperatures at mid-latitudes before the displaced warmings are not connected with a changed wave flux before the warming. In general, during the displaced events in 2009, 2010 and 2012 an increased PW wave activity (transient and stationary) between $30^{\circ} \mathrm{N}$ and $50^{\circ} \mathrm{N}$ compared to that in 2006 is observed.

We also found a hint for a connection of the latitudinal displacement of SSWs and the QBO phase.

An effect that occurs beside these differences is a midlatitudinal warming in the mesosphere around the SSWs during all displacement events considered in this study. This is caused by an increased stationary wave 1 activity between $30^{\circ} \mathrm{N}$ and $50^{\circ} \mathrm{N}$ in the mesosphere around the warmings.

In addition, during all events considered in this study an equatorward movement of the stratospheric warming and a downward progression of the zonal wind and temperature changes is observed.

This study does not only reveal latitudinal differences but also longitudinal variability in both, wind and temperature observations. These longitudinal differences seem to arise from the phasing of stationary and transient waves. At this point further investigations are needed to fit local measurements and zonal mean observations better together with circulation models into the global context. This issue will be considered in a future work.

Acknowledgements. We thank the Jet Propulsion Laboratory/NASA for providing access to the Aura/MLS level 2.2 retrieval products. We acknowledge the Global Modelling and Assimilation Office (GMAO) and the GES DISC for the dissemination of MERRA. We wish to thank Ralph Latteck, Werner Singer and Dieter Keuer for their permanent support using the Meteor and MF-radars at Andenes and Juliusruh. We thank also Gerd Baumgarten for providing MERRA data and Christoph Zülicke and the ISSI team 217 for their helpful discussions. Last but not least, we thank Timo Viehl for his grammatical corrections.

Topical Editor C. Jacobi thanks two anonymous referees for their help in evaluating this paper.

\section{References}

Andrews, D. G., Holton, J. R., and Leovy, C. B.: Middle atmosphere dynamics, Academic Press, 1987.

Cevolani, G.: Strato-meso-thermospheric coupling at mid-latitudes in the course of mid-winter stratwarmings during DYANA, Geophys. Res. Lett., 18, 1987-1990, 1991. 
Charlton, A. J. and Polvani, L. M.: A New look at stratospheric sudden warmings, Part I: Climatology and modeling Benchmarks, J. Climate, 20, 449-469, 2007.

Chen, W. and Huang, R.-H.: The modulation of planetary wave propagation by the tropical QBO zonal winds and the associated effects in the residual meridional circulation, Contrib. Atmos. Phys., 72, 187-204, 1999.

Chen, X., Hu, X., and Xiao, C.: Variability of MLT winds and waves over mid-latitude during the 2000/2001 and 2009/2010 winter stratospheric sudden warming, Ann. Geophys., 30, 991-1001, doi:10.5194/angeo-30-991-2012, 2012.

Coy, L., Eckermann, S. D., Hoppel, K. W., and Sassi, F.: Mesospheric Precursors to the Major Stratospheric Sudden Warming of 2009: Validation and Dynamical Attribution Using a Groundto-Edge-of-Space Data Assimilation System, J. Adv. Model. Earth Syst., 3, doi:10.1029/2011MS000067, 2011.

De La Torre, L., Garcia, R. R., Barriopedro, D., and Chandran, A.: Climatology and characteristics of stratospheric sudden warmings in the Whole Atmosphere Community Climate Model, J. Geophys. Res., 117, D04110, doi:10.1029/2011JD016840, 2012.

Fritz, S. and Soules, S. D.: Large-Scale Temperature Changes in the Stratosphere Observed from Nimbus III, J. Atmos. Sci., 27, 1091-1097, doi:10.1175/15200469(1970)027<1091:LSTCIT>2.0.CO;2, 1970.

Froidevaux, L., Livesey, N., Read, W., Jiang, Y., Jimenez, C., Filipiak, M., Schwartz, M., Santee, M., Pumphrey, H., Jiang, J., Wu, D., Manney, G., Drouin, B., Waters, J., Fetzer, E., Bernath, P., Boone, C., Walker, K., Jucks, K., Toon, G., Margitan, J., Sen, B., Webster, C., Christensen, L., Elkins, J., Atlas, E., Lueb, R., and Hendershot, R.: Early validation analyses of atmospheric profiles from EOS MLS on the aura Satellite, Geoscience and Remote Sensing, IEEE Transactions on, 44, 11061121, doi:10.1109/TGRS.2006.864366, 2006.

Gregory, J. B. and Manson, A. H.: Wind and waves to $110 \mathrm{~km}$ at mid-latitudes: III. Responses of mesospheric and lower thermospheric winds to major stratospheric warmings, J. Atmos. Sci., 32, 1676-1681, 1975.

Hocking, W., Fuller, B., and Vandepeer, B.: Real-time determination of meteor-related parameters utilizing modern digital technology, J. Atmos. Solar-Terr. Phys., 63, 155-169, 2001.

Hocking, W., Singer, W., Bremer, J., Mitchell, N., Batista, P., Clemesha, B., and Donner, M.: Meteor radar temperatures at multiple sites derived with SKiYMET radars and compared to $\mathrm{OH}$, rocket and lidar measurements, J. Atmos. Solar-Terr. Phys., 66, 585-593, 2004.

Hoffmann, P., Singer, W., and Keuer, D.: Variability of the mesospheric wind field at middle and Arctic latitudes in winter and its relation to stratospheric circulation disturbances, J. Atmos. Solar-Terr. Phys., 64, 1229-1240, 2002.

Hoffmann, P., Singer, W., Keuer, D., Hocking, W. K., Kunze, M., and Murayama, Y.: Latitudinal and longitudinal variability of mesospheric winds and temperatures during stratospheric warming events, J. Atmos. Solar-Terr. Phys., 69, 2355-2366, doi:10.1016/j.jastp.2007.06.010, 2007.

Keuer, D., Hoffmann, P., Singer, W., and Bremer, J.: Longterm variations of the mesospheric wind field at mid-latitudes, Ann. Geophys., 25, 1779-1790, doi:10.5194/angeo-25-17792007, 2007.
Kodera, K.: Influence of stratospheric sudden warming on the equatorial troposphere, Geophys. Res. Lett., 33, L06804, doi:10.1029/2005GL024510, 2006.

Kurihara, J., Ogawa, Y., Oyama, S., Nozawa, S., Tsutsumi, M., Hall, C. M., Tomikawa, Y., and Fujii, R.: Links between a stratospheric sudden warming and thermal structures and dynamics in the high-latitude mesosphere, lower thermosphere, and ionosphere, Geophys. Res. Lett., 37, L13806, doi:10.1029/2010GL043643, 2010.

Labitzke, K.: On the signal of the 11-year sunspot cycle in the stratosphere over the Antarctic and its modulation by the Quasi-Biennial Oscillation (QBO), METZ, 13, 263-270, doi:10.1127/0941-2948/2004/0013-0263, 2004.

Labitzke, K. and Kunze, M.: On the remarkable Arctic winter in 2008/2009, J. Geophys. Res.: Atmospheres, 114, D00102, doi:10.1029/2009JD012273, 2009.

Labitzke, K. and Naujokat, B.: The lower Arctic stratosphere in winter since 1952, SPARC Newsletter, 15, 11-14, 2000.

Limpasuvan, V., Thompson, D. W. J., and Hartmann, D. L.: The life cycle of the Northern Hemisphere sudden stratospheric warmings, JC, 17, 2584-2596, doi:10.1175/15200442(2004)017<2584:TLCOTN>2.0.CO;2, 2004.

Limpasuvan, V., Richter, J. H., Orsolini, Y. J., Stordal, F., and Kvissel, O.-K.: The roles of planetary and gravity waves during a major stratospheric sudden warming as characterised in WACCM, J. Atmos. Solar-Terr. Phys., 78-79, 84-98, doi:10.1016/j.jastp.2011.03.004, 2012.

Livesey, N. J., Read, W. G., Lambert, A., Cofield, R. E., Cuddy, D. T., Froidevaux, L., Fuller, R. A., Jarnot, R. F., Jiang, J. H., Jiang, Y. B., Knosp, B. W., Kovalenko, L. J., Pickett, H. M., Pumphrey, H. C., Santee, M. L., Schwartz, M. J., Stek, P. C., Wagner, P. A., Waters, J. W., and Wu, D. L.: EOS MLS Version 2.2 Level 2 data quality and description document, Technical Report, Version 2.2 D-33509, Jet Propulsion Lab., California Institute of Technology, Pasadena, California, 91198-8099, 2007.

Lucchesi, R.: File Specification for MERRA Products, GMAO Office Note No. 1 (Version 2.3), 82 pp., available from http://gmao. gsfc.nasa.gov/pubs/office_notes, 2012.

Manney, G. L., Krüger, K., Pawson, S., Minschwaner, K., Schwartz, M. J., Daffer, W. H., Livesey, N. J., Mlynczak, M. G., Remsberg, E. E., Russell, J. M., and Waters, J. W.: The evolution of the stratopause during the 2006 major warming: Satellite data and assimilated meteorological analyses, J. Geophys. Res.: Atmospheres, 113, D11115, doi:10.1029/2007JD009097, 2007.

Manney, G. L., Schwartz, M. J., Krüger, K., Santee, M. L., Pawson, S., Lee, J. N., Daffer, W. H., Fuller, R. A., and Livesey, N. J.: Aura Microwave Limb Sounder observations of dynamics and transport during the record-breaking 2009 Arctic stratospheric major warming, Geophys. Res. Lett., 36, doi:10.1029/2009GL038586, 2009.

Manson, A. H., Meek, C., Chshyolkova, T., McLandress, C., Avery, S. K., Fritts, D. C., Hall, C. M., Hocking, W. K., Igarashi, K., MacDougall, J. W., Murayama, Y., Riggin, C., Thorsen, D., and Vincent, R. A.: Winter warmings, tides and planetary waves: comparisions between CMAM (with interactive chemistry) and MFR-MetO observations and data, Ann. Geophys., 24, 24932518, doi:10.5194/angeo-24-2493-2006, 2006.

Matsuno, T.: A dynamical model of the stratospheric sudden warming, J. Atmos. Sci., 28, 1479-1494, doi:10.1175/1520- 
0469(1971)028<1479:ADMOTS > 2.0.CO;2, 1971.

Matthias, V., Hoffmann, P., Rapp, M., and Baumgarten, G.: Composite analysis of the temporal development of waves in the polar MLT region during stratospheric warmings, J. Atmos. Solar-Terr. Phys., 90-91, 86-96, doi:10.1016/j.jastp.2012.04.004, 2012.

McDonald, A. J., Hibbins, R. E., and Jarvis, M. J.: Properties of the quasi 16 day wave derived from EOS MLS observations, J. Geophys. Res., 116, D06112, doi:10.1029/2010JD014719, 2011.

Meek, C. E. and Manson, A. H.: Mesospheric motions observed by simultaneous medium-frequency interferometer and spaced antenna experiments, J. Geophys. Res., 92, 5627-5639, doi:10.1029/JD092iD05p05627, 1987.

Meek, C. E. and Manson, A. H.: Summer planetary-scale oscillations: aura MLS temperature compared with ground-based radar wind, Ann. Geophys., 27, 1763-1774, doi:10.5194/angeo-271763-2009, 2009.

Mukhtarov, P., Pancheva, D., Andonov, B., Mitchell, N. J., Merzlyakov, E., Singer, W., Hocking, W., Meek, C., Manson, A., and Murayama, Y.: Large-scale thermodynamics of the stratosphere and mesosphere during the major stratospheric warming in 2003/2004, J. Atmos. Solar-Terr. Phys., 69, 2338-2354, doi:10.1016/j.jastp.2007.07.012, 2007.

Naito, Y. and Yoden, S.: Behaviour of Planetary Waves before and after Stratospheric Sudden Warming Events in Several Phases of the Equatorial QBO, J. Atmos. Sci., 63, 1637-1649, doi:10.1175/JAS3702.1, 2006.

Orsolini, Y. J., Urban, J., Murtagh, D. P., Lossow, S., and Limpasuvan, V.: Descent from the polar mesosphere and anomalously high stratopause observed in 8 years of water vapor and temperature satellite observations by the Odin Sub-Millimeter Radiometer, J. Geophys. Res., 115, doi:10.1029/2009JD013501, 2010.

Pancheva, D., Mukhtarov, P., Andonov, B., Mitchell, N. J., and Forbes, J. M.: Planetary waves observed by TIMED/SABER in coupling the stratosphere-mesosphere-lower thermosphere during the winter of 2003/2004: Part 2 - Altitude and latitude planetary wave structure, J. Atmos. Solar-Terr. Phys., 71, 75-87, doi:10.1016/j.jastp.2008.09.027, 2009.

Plumb, R. A.: On the Three-Dimensional Propagation of Stationary Waves, J. Atmos. Sci., 42, 217-229, doi:10.1175/15200469(1985)042<0217:OTTDPO > 2.0.CO;2, 1985.

Rienecker, M. M., Suarez, M. J., Gelaro, R., Todling, R., Bacmeister, J., Liu, E., Bosilovich, M. G., D.Schubert, S., Kim, L. T. G.-K., Bloom, S., Chen, J., Collins, D., Conaty, A., da Silva, A., Gu, W., Joiner, J., Koster, R. D., Lucchesi, R., Molod, A., Owens, T., Pawson, S., Pegion, P., Redder, C. R., Reichle, R., Robertson, F. R., Ruddick, A. G., Sienkiewicz, M., and Woollen, J.: MERRA: NASA's Modern-Era Retrospective Analysis for Research and Applications, J. Climate, 24, 0894-8755, doi:10.1175/JCLI-D-11-00015.1, 2011.

Schwartz, M. J., Lambert, A., Manney, G. L., Read, W. G., Livesey, N. J., Froidevaux, L., Ao, C. O., Bernath, P. F., Boone, C. D., Cofield, R. E., Daffer, W. H., Drouin, B. J., Fetzer, E. J., Fuller, R. A., Jarnot, R. F., Jiang, J. H., Jiang, Y. B., Knosp, B. W., Krüger, K., Li, J.-L. F., Mlynczak, M. G., Pawson, S., Russell, J. M., Santee, M. L., Snyder, W. V., Stek, P. C., Thurstans, R. P., Tompkins, A. M., Wagner, P. A., Walker, K. A., Waters, J. W., and $\mathrm{Wu}, \mathrm{D}$. L.: Validation of the Aura Microwave Limb Sounder temperature and geopotential height measurements, J. Geophys. Res., 113, D15S11, doi:10.1029/2007JD008783, 2008.
Shepherd, M., Wu, D., Fedulina, I., Gurubaran, S., Russell, J., Mlynczak, M., and Shepherd, G.: Stratospheric warming effects on the tropical mesospheric temperature field, J. Atmos. SolarTerr. Phys., 69, 2309-2337, doi:10.1016/j.jastp.2007.04.009, 2007.

Shepherd, M. G., Cho, Y., Shepherd, G. G., Ward, W., and Drummond, J. R.: Mesospheric temperature and atomic oxygen response during the January 2009 major stratospheric warming, J. Geophys. Res., 115, A07318, doi:10.1029/2009JA015172, 2009.

Singer, W., Hoffmann, P., Manson, A. H., Meek, C. E., Schminder, R., Kürschner, D., Kokin, G. A., Knyazev, A. K., Portnyagin, Y. I., Makarov, N. A., Fakhrudtinova, A. N., Sidorov, V. V., Cevolani, G., Muller, H. G., Kazimirovsky, E. S., Gaidukov, V. A., Clark, R. R., Chebotarev, R. P., and Karadjaev, Y.: The wind regime of the mesosphere and lower thermosphere during the DYANA campaign - I. Prevailing winds, J. Atmos. Terr. Phys., 56, 1717-1729, doi:10.1016/0021-9169(94)90006X, 1994.

Singer, W., Bremer, J., Hocking, W. K., Weiss, J., Latteck, R., and Zecha, M.: Temperature and wind tides around the summer mesopause at middle and Arctic latitudes, Adv. Space Res., 31, 2055-2060, doi:10.1016/S0273-1177(03)00228-X, 2003.

Stober, G., Jacobi, C., Matthias, V., Hoffmann, P., and Gerding, M.: Neutral air density variations during strong planetary wave activity in the mesopause region derived from meteor radar observations, J. Atmos. Solar-Terr. Phys., 74, 55-63, doi:10.1016/j.jastp.2011.10.007, 2012.

Tomikawa, Y., Sato, K., Watanabe, S., Kawatani, Y., Miyazaki, K., and Takahashi, M.: Growth of planetary waves and the formation of an elevated stratopause after a major stratospheric sudden warming in a T213L256 GCM, J. Geophys. Res.: Atmospheres, 117, D16101, doi:10.1029/2011JD017243, 2012.

Torrence, C. and Compo, G. P.: A practical guide to wavelet analysis, B. Am. Meteorol. Soc., 79, 61-78, doi:10.1175/15200477(1998)079<0061:APGTWA>2.0.CO;2, 1998.

Tunbridge, V. M., Sandford, D. J., and Mitchell, N. J.: Zonal wave numbers of the summertime 2 day planetary wave observed in the mesosphere by EOS Aura Microwave Limb Sounder, J. Geophys. Res., 116, D11103, doi:10.1029/2010JD014567, 2011.

Waters, J. W., Froidevaux, L., Harwood, R. S., Jarnot, R. F., Pickett, H. M., Read, W. G., Siegel, P. H., Cofield, R. E., Filipiak, M. J., Flower, D. A., Holden, J. R., Lau, G. K., Livesey, N. J., Manney, G. L., Pumphrey, H. C., Santee, M. L., Wu, D. L., Cuddy, D. T., Lay, R. R., Loo, M. S., Perun, V. S., Schwartz, M. J., Stek, P. C., Thurstans, R. P., Boyles, M. A., Chandra, K. M., Chavez, M. C., Chen, G.-S., Chudasama, B. V., Dodge, R., Fuller, R. A., Girard, M. A., Jiang, J. H., Jiang, Y., Knosp, B. W., LaBelle, R. C., Lam, J. C., Lee, K. A., Miller, D., Oswald, J. E., Patel, N. C., Pukala, D. M., Quintero, O., Scaff, D. M., Van Snyder, W., Tope, M. C., Wagner, P. A., and Walch, M. J.: The Earth Observing System Microwave Limb Sounder (EOS MLS) on the Aura Satellite, IEEE T. GRS, 44, 5, D18108, 1075-1092, doi:10.1109/TGRS.2006.873771, 2006.

Wu, D. L., Hays, P. B., and Skinner, W. R.: A Least Squares Method for Spectral Analysis of Space-Time Series, J. Atmos. Sci., 52, 3501-3511, doi:10.1175/15200469(1995)052<3501:ALSMFS > 2.0.CO;2, 1995. 
Yoo, J.-M., Won, Y.-I., Jeong, M.-J., Kim, K.-M., Shin, D.-B., Lee, Y.-R., and Cho, Y.-J.: Intensity of Climate Variability Derived from the Satellite and MERRA Reanalysis Temperatures: AO, ENSO, and QBO, J. Atmos. Solar-Terr. Phys., 95-96, 13646826, doi:10.1016/j.jastp.2013.01.002, 2013. 